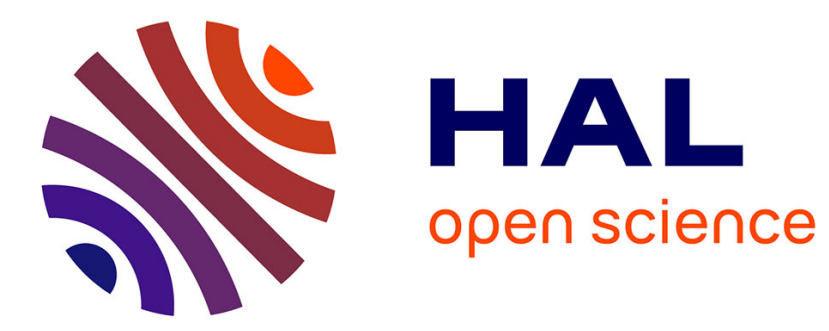

\title{
Tensile properties and fracture toughness at service temperatures of an optimized pearlitic ductile iron alloy for automotive crankshafts
}

\author{
G. Artola, A. Monzón, J. Lacaze, J. Sertucha
}

\section{- To cite this version:}

G. Artola, A. Monzón, J. Lacaze, J. Sertucha. Tensile properties and fracture toughness at service temperatures of an optimized pearlitic ductile iron alloy for automotive crankshafts. Materials Science and Engineering: A, 2022, 831, pp.142206. 10.1016/j.msea.2021.142206 . hal-03406162

\author{
HAL Id: hal-03406162 \\ https://hal.science/hal-03406162
}

Submitted on 27 Oct 2021

HAL is a multi-disciplinary open access archive for the deposit and dissemination of scientific research documents, whether they are published or not. The documents may come from teaching and research institutions in France or abroad, or from public or private research centers.
L'archive ouverte pluridisciplinaire HAL, est destinée au dépôt et à la diffusion de documents scientifiques de niveau recherche, publiés ou non, émanant des établissements d'enseignement et de recherche français ou étrangers, des laboratoires publics ou privés. 
Tensile properties and fracture toughness at service temperatures of an optimized pearlitic ductile iron alloy for automotive crankshafts

G. Artola ${ }^{1}$, A. Monzón ${ }^{2}$, J. Lacaze ${ }^{3}$ and J. Sertucha ${ }^{1}$

1 Azterlan, Basque Research and Technology Alliance, Aliendalde Auzunea 6, E-48200 Durango

(Bizkaia), Spain.

2 Draxton-Teruel, Polígono Los Llanos, E-44760 Utrillas (Teruel), Spain.

3 CIRIMAT, Université de Toulouse, 4 allée Monso, BP 44362, 31030 Toulouse, France.

\begin{abstract}
Cast iron and forged steel have competed against each other for many years for different industrial applications. Crankshafts are one of the products where this competition is still active, both for heavy duty and light machinery applications. For the specific case of automotive crankshafts, high strength pearlitic cast iron grades have found a strong position in passenger car market niches. The mechanical performance data available for these specific ductile cast iron grades mostly come from room temperature tensile and impact testing. Nevertheless, the failure mode of cast iron crankshafts involves fracture mechanics, and their usual range of working temperatures goes from $-20^{\circ} \mathrm{C}$ for cold starts to $120^{\circ} \mathrm{C}$ for top maximum lubricating oil temperature. This work covers this range by studying a high strength pearlitic cast iron employed to manufacture crankshafts both in terms of tensile, impact and fracture mechanics testing at $-20^{\circ} \mathrm{C}, 22^{\circ} \mathrm{C}$ and $120^{\circ} \mathrm{C}$. A specific molding pattern was designed to produce the desired materials, namely crankshafts and Y2 and Y3 wedges, which were cast in an industrial crankshaft manufacturing line. The results indicate that there is a relevant difference between the low temperature and the high temperature mechanical response of the studied cast iron. This finding is interpreted in terms of safety, as the crankshafts should not fail in service after the engine has started running and the lubrication has reached its steady state working temperature.
\end{abstract}

Keywords: Ductile iron, fully pearlitic structure, mechanical properties, fracture toughness, automotive castings, crankshafts

\title{
1. INTRODUCTION AND BACKGROUND
}

The competition between cast irons and steels in the manufacture of certain metallic parts is a subject of industrial interest since the 1970s [1]. There is a specific structural difference between both materials which is related to the formation and growth of graphite particles in the metallic matrix of cast irons due to their comparatively high carbon and silicon contents. Spheroidal graphite particles in ductile cast irons strongly affect both solidification process and the austenite transformation that determine the final structure observed at room temperature [2]. The relevant development of these cast alloys is such that the required structures can be commonly obtained without any heat treatment by controlling the content of some alloying elements. As the main mode of failure of high-security parts for both cast iron and steel [3-6] is fatigue fracture, the combination of their cost and resistance to mechanical damage becomes the factor of competitive advantage. In this context, both cast iron grades and steel grades have evolved in an attempt to broaden their field of application, though remaining niche markets with differentiated technical-economic requirements.

From an economic point of view, there is little information available to clarify the conditions under which cast iron gains an advantage over forged steel, being the work of Nallicheri et al. [7] in 1990s 
a very used reference [8-10]. Fortunately, this work is still illustrative as it reflects general trends. On the one hand, these authors present a scenario in which ductile cast iron is more costcompetitive than forged steel for producing as-cast crankshafts, except for high production volumes (Figure 1a) mainly due to tooling and machining related costs. However, it is also reported that cast iron parts become the best solution in terms of cost of finished components (including all finishing operations) regardless of the volume of production (Figure $1 b$ ).
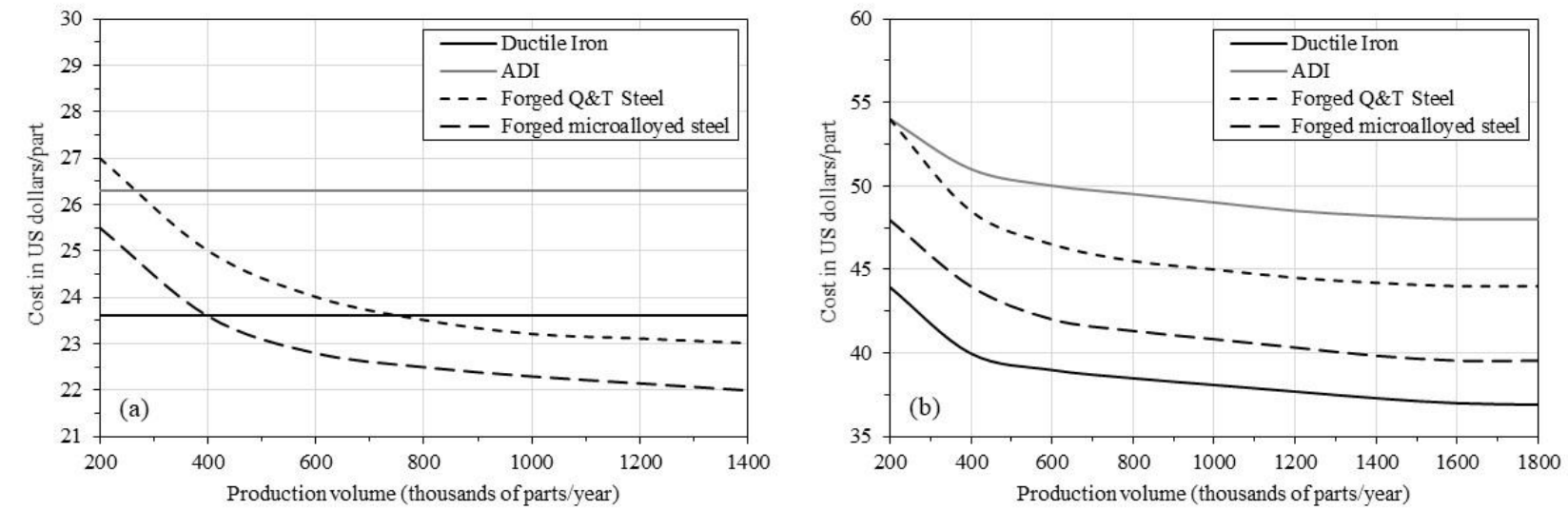

Figure 1. Cost comparison from the 90's on (a) as-cast and (b) finished crankshafts adapted from Nallicheri et al. [7]. Data from a generic quenching and tempering steel (Q\&T) and a micro-alloyed steel have been also included as forged for comparison. ADI stands for Austempered Ductile Iron.

Considering the cost differences between a part produced using a cast iron alloy and by forging a conventional quenched and tempered steel, it does not seem to make economic sense to employ forged crankshafts. The use of forged parts is justified, not by economic aspects, but by the advantages they offer in terms of assurance of internal soundness and alignment of the grain fibers with the main directions of the loads applied to the component in service [9]. In general terms, cast iron parts cover the market governed by the performance/cost trade-off, while forged parts monopolize the niches in which the toughness and mechanical resistance prevail over the price.

Today, cast iron technology has evolved to more robust manufacturing processes, which widely ensure the internal soundness of the parts, and to the use of controlled cooling conditions or even specific heat treatments which allow achieving mechanical strengths capable of penetrating market segments of forged steel parts. On the other side, forging has adopted the use of micro-alloyed steels which allow the removal of the subsequent heat treatments and improve machinability. This has increased the cost competitiveness of the forged parts thus manufactured. The fact that Austempered Ductile Iron (ADI), which is a special type of heat-treated cast iron, and microalloyed steels are present in cost studies like the one presented in Figure 1 shows that these improvement strategies were already considered in early developments, and they remain valid today [10-11].

In this scenario, high strength pearlitic ductile cast irons have become very attractive in terms of performance/cost ratio, due to the excellent combination of price and mechanical properties they offer. As a result of previous investigations [12-13] (and references therein), a group of optimized fully pearlitic ductile iron alloys was developed in terms of chemical composition and cooling rate with ultimate tensile strength and yield strength values higher than $900 \mathrm{MPa}$ and 550-600 MPa, respectively, while keeping relevant elongation at rupture (2-6\%). Although, these results evidenced such materials as a cheap alternative to forged parts, these studies were carried out only in terms of tensile properties at room temperature that are not enough when it comes to exploring the application potential of these improved pearlitic ductile irons. Accordingly, this work investigates the mechanical behavior of automotive crankshafts produced with optimized material, both in terms 
of plastic ductile failure and of fracture mechanics, as required for high strength alloys, and also explores the effect of the temperature in extreme operating conditions, namely $-20^{\circ} \mathrm{C}$ and $120^{\circ} \mathrm{C}$.

\section{EXPERIMENTAL WORK}

The present study involves three different cast parts, namely, two standard wedges designed as Y2 and Y3 (according to the EN-1563:2012 standard) and one automotive crankshaft $12.0 \mathrm{~kg}$ in weight (Figure 2). This last cast part will be the reference casting in this work as it is regularly produced with pearlitic ductile iron alloys in a foundry plant which supplies crankshafts to several automotive constructors. It has been established that the most relevant areas of this crankshaft are the two diagonals along two opposite rod bearing journals as indicated in Figure 2 with dashed rectangles. These areas are considered of high interest due to their critical role during the life span of combustion engines and they were used for obtaining the tensile and impact specimens.

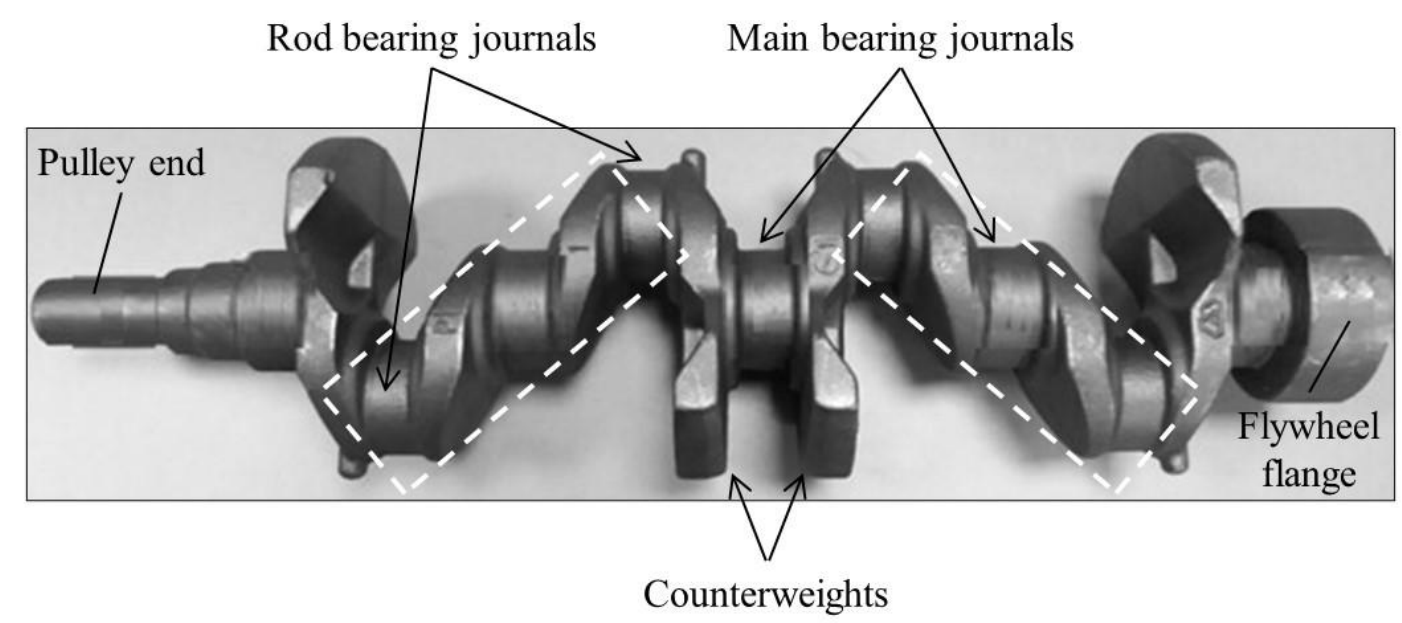

Figure 2. Crankshaft used in the present work. The critical areas have been marked with dashed rectangles and they have been used for obtaining the testing specimens from this casting type.

The smallest wedge (Y2) was selected as it is widely used as standard casting for mechanical testing and this allows the comparison of the results obtained with other previous and future results. The heaviest wedge (Y3) was used to carry out the fracture toughness study which, in general, requires using a specimen thickness as close as possible to the thickness of the component of interest. In this case the selected section of the crankshaft has a thickness of $50 \mathrm{~mm}$ and it corresponds to the diameter of all rod and main bearing journals (Figure 2). Consequently, bending specimens of thickness $\mathrm{B}=40 \mathrm{~mm}$ were all machined out from the $\mathrm{Y} 3$ wedges (see subsequent description) since it is the thickness closest to $50 \mathrm{~mm}$ for which test tools were available. The geometric characteristics of the two different wedges are shown in Figure 3. All the cast parts used in this work were manufactured and then used to obtain the corresponding tensile and toughness fracture samples without any heat treatment. 


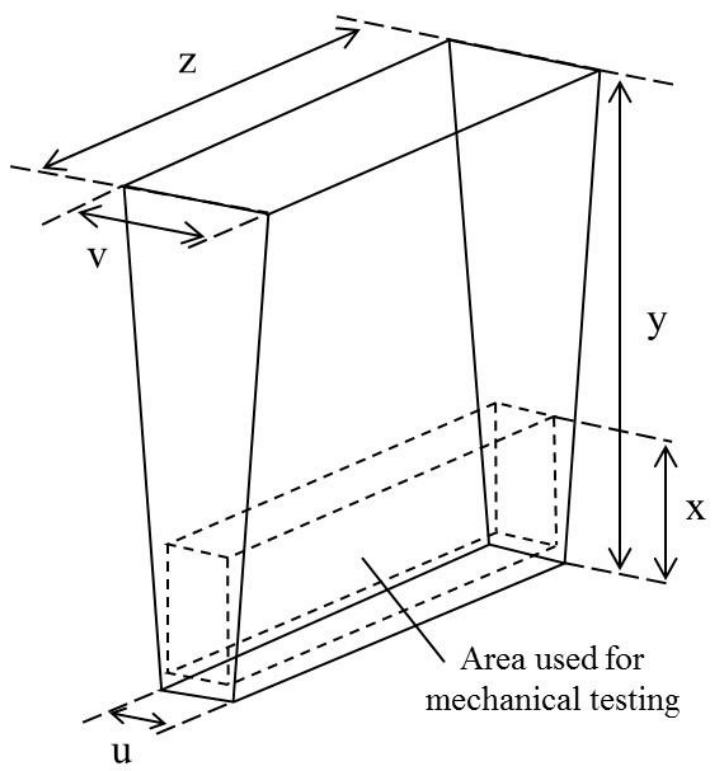

\begin{tabular}{|c|c|c|}
\hline \multirow{2}{*}{$\begin{array}{c}\text { Dimension } \\
(\mathrm{mm})\end{array}$} & \multicolumn{2}{|c|}{ Wedge type } \\
\cline { 2 - 3 } & $\mathrm{Y} 2$ & $\mathrm{Y} 3$ \\
\hline $\mathrm{u}$ & 25 & 50 \\
\hline $\mathrm{v}$ & 55 & 100 \\
\hline $\mathrm{x}$ & 40 & 50 \\
\hline $\mathrm{y}$ & 140 & 150 \\
\hline $\mathrm{z}$ & 150 & 430 \\
\hline
\end{tabular}

Figure 3. Dimensions of the wedges used in this work (adapted from EN 1563:2012).

All cast parts were produced with a single pattern plate which included two crankshafts, four Y2 wedges and one Y3 wedge according to the distribution shown in Figure 4 which corresponds to the drag plate. The filling system was composed of a down sprue, two filter chambers and runners with different sections. Only the two crankshaft cavities had feeders to avoid the formation of shrinkage porosities in these parts. The testing area indicated in Figure 3 was located at the bottom of the molds to ensure that contraction porosities were not present in this area of the Y2 and Y3 wedges.

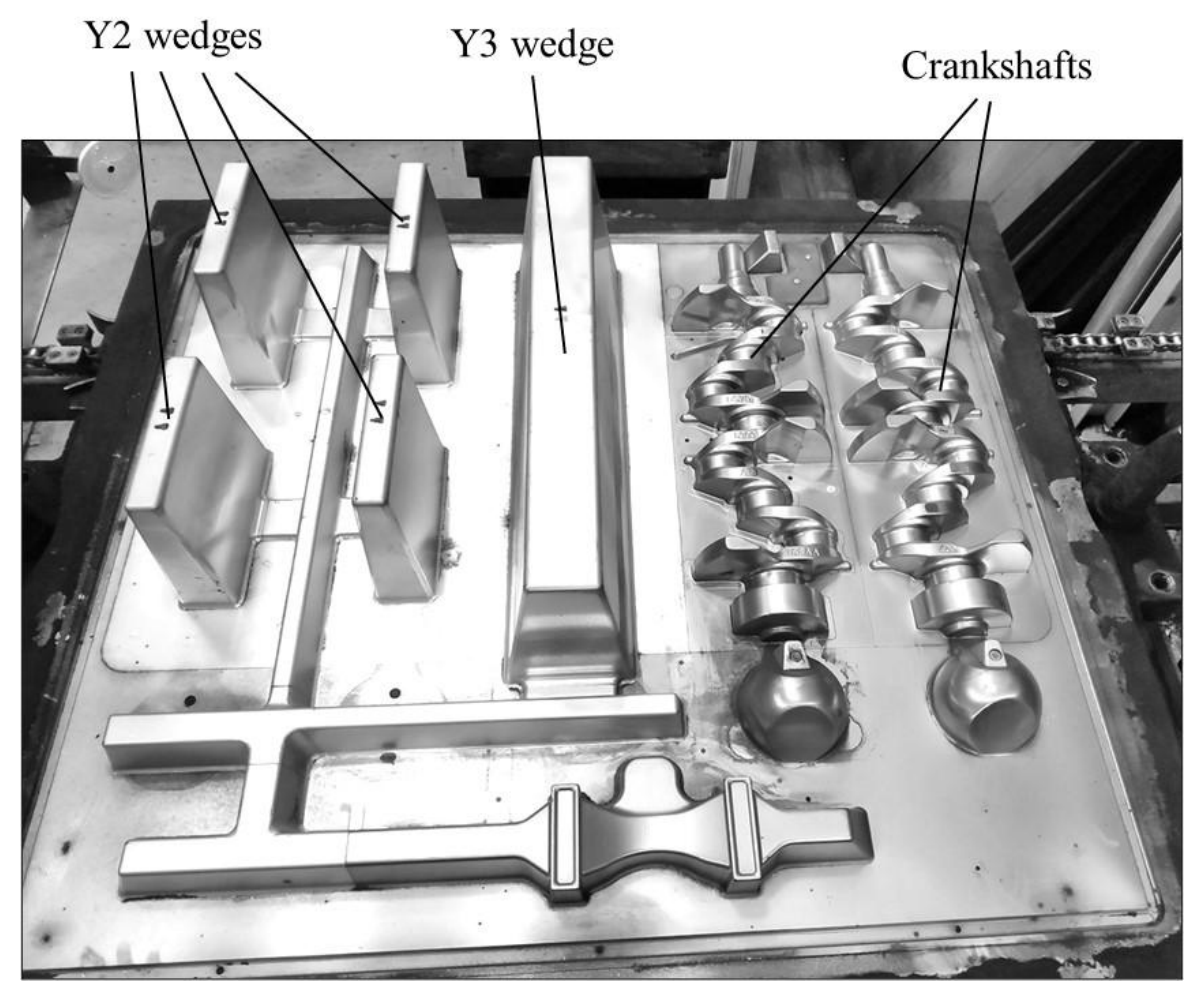

Figure 4. Distribution of the cast parts in the drag pattern plate used to produce the molds.

The base melt batch used in the present investigation was prepared in a medium frequency induction furnace $(250 \mathrm{~Hz}, 12000 \mathrm{~kW})$ with $16 \mathrm{t}$ in capacity. The metallic charges were composed of about $45 \%$ steel scrap and 55\% ductile iron returns. After completing the melting process, the chemical composition of the batch was checked and then adjusted adding the corresponding 
ferroalloys. The carbon and silicon contents were corrected, respectively, with a high purity graphite (>98.9 wt.\%) and a FeSi75 alloy (grain size $10-90 \mathrm{~mm}, \mathrm{Si}=75.2, \mathrm{Ca}=0.26, \mathrm{Al}=0.86, \mathrm{C}$ $=0.13$ and $\mathrm{Fe}$ balance, wt.\%). The melt temperature was then increased to $1510-1520^{\circ} \mathrm{C}$ and the slag was removed. Afterwards, the prepared melt was transferred in two batches to a $3300 \mathrm{~kg}$ capacity ladle which contained $26-33 \mathrm{~kg}(0.8-1.0 \mathrm{wt} . \%$ of the batch weight) of a FeSiMg alloy (grain size $2-10 \mathrm{~mm}, \mathrm{Si}=45.9, \mathrm{Mg}=5.7, \mathrm{Ca}=2.42, \mathrm{Al}=0.39$, rare earth elements $=2.24$ and $\mathrm{Fe}$ balance, wt.\%) to carry out the spheroidizing treatment by the tundish-cover method (1450$1470^{\circ} \mathrm{C}$ ). This FeSiMg alloy was positioned into a chamber located at the bottom of the ladle and then covered, first, with $5 \mathrm{~kg}$ of steel scrap and then, with $3.3 \mathrm{~kg}$ of a commercial inoculant (grain size $2-6 \mathrm{~mm}, \mathrm{Si}=75.1, \mathrm{Al}=1.50$ and $\mathrm{Ca}=0.96, \mathrm{Fe}$ balance, wt. $\%$ ) and finally with further steel scrap (grain size 15-30 mm). Once the spheroidizing treatment was finished, the two prepared batches were consecutively transferred to a $10 \mathrm{t}$ capacity pressurized pouring unit from which the molds were poured at $1360-1380^{\circ} \mathrm{C}$. During pouring, post-inoculation was performed by adding 0.15-0.18 wt.\% of a commercial inoculant (grain size $0.2-0.6 \mathrm{~mm}, \mathrm{Si}=64.1, \mathrm{Al}=0.85, \mathrm{Ca}=1.00$, $\mathrm{Mn}=3.30, \mathrm{Zr}=3.49$ and $\mathrm{Fe}$ balance, wt. $\%$ ) in the melt stream. A total number of 38 molds were poured to give $152 \mathrm{Y} 2$ wedges, $38 \mathrm{Y} 3$ wedges and 76 crankshafts.

A metal sample (medal) was obtained per batch when pouring the molds to determine the chemical composition of the melt. A combustion technique (LECO CS300) was then used for determining carbon and sulfur contents on the sample while spectrometry (ARL 3460) was utilized for other elements. Chemical compositions for all significant elements are shown in Table 1 which does not include the contribution of post-inoculation.

Table 1. Chemical composition of the melt batch used for producing all the cast parts (wt.\%).

\begin{tabular}{|c|c|c|c|c|c|c|}
\hline Batch & $\mathrm{C}$ & $\mathrm{Si}$ & $\mathrm{Mn}$ & $\mathrm{P}$ & $\mathrm{S}$ & $\mathrm{Cr}$ \\
\hline 1 & 3.61 & 2.26 & 0.44 & 0.022 & 0.006 & 0.042 \\
\hline 2 & 3.65 & 2.23 & 0.45 & 0.025 & 0.004 & 0.044 \\
\hline Batch & $\mathrm{Ni}$ & $\mathrm{Al}$ & $\mathrm{Cu}$ & $\mathrm{Sn}$ & $\mathrm{Ti}$ & $\mathrm{Mg}$ \\
\hline 1 & 0.021 & 0.009 & 0.84 & 0.024 & 0.024 & 0.036 \\
\hline 2 & 0.023 & 0.011 & 0.81 & 0.021 & 0.027 & 0.041 \\
\hline
\end{tabular}

60-70 min after pouring, all cast parts were removed from the molds, cooled down in open air until reaching room temperature and shot blasted to clean all their surfaces. Such time range of cooling into the molds was planned to reach about $600-650^{\circ} \mathrm{C}$ in the central area of the Y3 wedges when demolding started while the thinnest zones of the crankshafts (counterweights and pulley ends) were at about $300-400^{\circ} \mathrm{C}$ according to simulation results.

The cast parts from which each specimen was machined out were chosen at random from both production batches, so that any effect related to production order was randomly distributed. Table 2 shows a summary of the different tests performed in the present work, the relevant cast parts, the test temperatures, and the number of specimens used and of repeated measurements in each case.

Table 2. Outline of hardness and mechanical tests and conditions used in this work.

\begin{tabular}{|c|c|c|c|c|c|c|}
\hline \multirow{2}{*}{ Test } & \multicolumn{3}{|c|}{ No. of cast parts } & \multirow{2}{*}{$\begin{array}{c}\text { Temperature } \\
\left({ }^{\circ} \mathrm{C}\right)\end{array}$} & \multirow{2}{*}{$\begin{array}{c}\text { No. of repeated } \\
\text { measurements }\end{array}$} & \multirow{2}{*}{$\begin{array}{c}\text { No. of } \\
\text { specimens }\end{array}$} \\
\hline & $\mathrm{Y} 2$ & Y3 & Crankshaft & & & \\
\hline HBW & 6 & \multirow{3}{*}{18} & 6 & 22 & \multirow{4}{*}{$\begin{array}{c}6 \text { per cast part } \\
\text { and } \\
\text { temperature }\end{array}$} & 18 \\
\hline Tensile & 18 & & 18 & \multirow{3}{*}{$\begin{array}{l}-20,22 \\
\text { and } 120\end{array}$} & & 54 \\
\hline Impact (Charpy) & 6 & & 9 & & & 54 \\
\hline Fracture toughness & $\begin{array}{ll}-- \\
\end{array}$ & 18 & --- & & & 18 \\
\hline
\end{tabular}

Standard tensile strength specimens per ISO 6892-1 with $10 \mathrm{~mm}$ in diameter (cylindrical section) and calibrated length of $50 \mathrm{~mm}$ were machined out from the cast parts. On these specimens, the 
tensile strength UTS, the elongation at rupture A and the yield strength YS values were measured using a Zwick Z250 tensile testing equipment at a controlled actuator speed of $0.90 \mathrm{~mm} / \mathrm{min}$ in the range where YS was determined. According to the standard ISO 6892-1, this rate was then increased to $24.12 \mathrm{~mm} / \mathrm{min}$ to determine UTS and A. All tensile specimens were produced with threaded ends and elongation values were determined by using a Zwick integrated transverse extensometer with $0.10 \mu \mathrm{m}$ in resolution. For the impact strength determination $(\mathrm{Kv})$, the dimensions of the specimens were $10 \times 10 \times 55 \mathrm{~mm}$ with an ISO V notch as per ISO $148-1$ standard and they were tested in a Zwick 5111 apparatus. Finally, proportional bending specimens as per ASTM E399 standard with $40 \mathrm{~mm}$ in thickness and $80 \mathrm{~mm}$ in height (Figure 5) were prepared for the fracture toughness. The notches with a base radius of $0.25 \mathrm{~mm}$ were machined by wire electric discharge machining in the side facing the thickest section of the Y3 wedge. At the bottom of each notch, a crack was generated in a controlled way that meets the parameters indicated in the standard ASTM E399 to ensure that the value of the shape factor " $\mathrm{f}$ " is known and that there is no plasticization at the crack tip. Note here again that the thickness of the toughness specimens was similar to the diameter of the rod and main bearing journals of the crankshafts $(50 \mathrm{~mm})$. An Instron 300DX apparatus with an environmental chamber MTS 651.06E-03 was used to perform the fracture toughness tests. This chamber was equipped with a forced air system to ensure the homogeneity of the temperature inside.

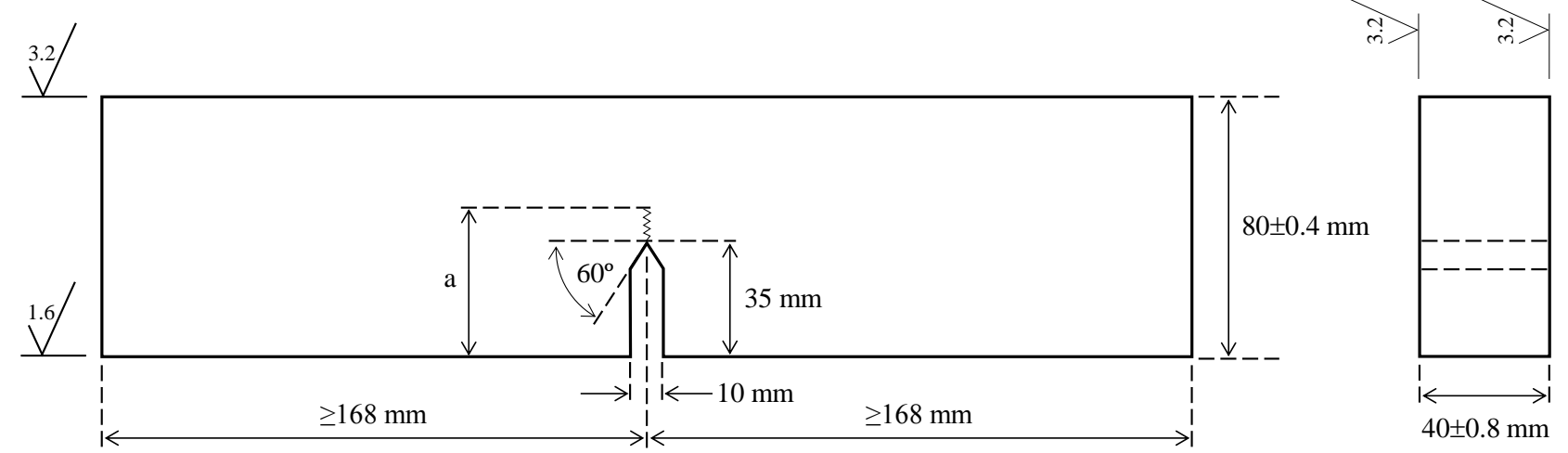

Figure 5. Characteristics of the toughness specimens used in this work [14]. Roughness requirements of the flat surfaces have been indicated in $\mu \mathrm{m}(\mathrm{Ra})$.

The most widespread approach to the mechanical design of components is based on the calculation of the conditions under which plastic collapse occurs, employing YS and UTS as key material properties for calculations. However, this design strategy is no longer valid when working with very high strength materials, relatively thick thicknesses and in the presence of cracks. In these circumstances, the risk for the component to break in a brittle way increases, which introduces the need for fracture mechanics. Toughness expressed in terms of the critical stress intensity factor, $\mathrm{K}_{\mathrm{IC}}$, becomes the key material property. The $\mathrm{K}_{\mathrm{IC}}$ value is calculated using the shape factor " $\mathrm{f}$ "and the depth of crack "a" (see Figure 5) according to equation 1 [14].

$$
\mathrm{K}_{\mathrm{IC}}=\frac{\mathrm{F}_{\mathrm{Q}} \mathrm{S}}{\sqrt{\mathrm{B}^{2}} \mathrm{~W}^{3 / 2}} \mathrm{f}\left(\frac{\mathrm{a}}{\mathrm{W}}\right)
$$

where $\mathrm{K}_{\mathrm{IC}}$ is the toughness of the material $\left(\mathrm{MPa} \cdot \mathrm{m}^{1 / 2}\right), \mathrm{F}_{\mathrm{Q}}$ is the force at the point of deviation of the linear elastic behavior $(\mathrm{N}), \mathrm{S}$ is the distance between the points of support of the specimen in the three point bending setup (m), "a" is the depth of the crack in the material that includes the length of the machined notch plus a sharp crack grown in a controlled manner by mechanical fatigue $(\mathrm{m}), \mathrm{W}$ and $B$ are the width and the thickness of the specimen $(m)$, respectively, and $f\left(\frac{a}{W}\right)$ is the shape factor to consider the modification of the stress state at the tip of the crack (dimensionless). This shape factor is given by [14]: 


$$
f\left(\frac{a}{W}\right)=3 \sqrt{\frac{a}{W}} \frac{1.99-\left(\frac{a}{w}\right)\left(1-\frac{a}{w}\right)\left[2.15-3.93 \frac{a}{w}+2.7\left(\frac{a}{w}\right)^{2}\right]}{2\left(1+2 \frac{a}{w}\right)\left(1-\frac{a}{w}\right)^{3 / 2}}
$$

As detailed in Table 2, three different temperatures were selected to investigate the effect of this parameter on mechanical results. In addition to room temperature, used as reference, a group of specimens was also tested at $-20^{\circ} \mathrm{C}$ and another at $120^{\circ} \mathrm{C}$ which are the temperatures that represent the engine start in cold climates and in overheated oil conditions, respectively. Thus, conditioning systems were used to maintain the specimens at the selected temperatures for a while before testing. Before impact testing, the samples were hold either $20 \mathrm{~min}$ in a cryostat at $-20^{\circ} \mathrm{C}$ or $60 \mathrm{~min}$ in a furnace maintained at $120^{\circ} \mathrm{C}$. The impact tests were performed in less than $3 \mathrm{~s}$ after extraction of the specimen from the temperature conditioning system. For the tensile and fracture toughness tests at $-20^{\circ} \mathrm{C}$ and $120^{\circ} \mathrm{C}$, the environmental chamber was kept running for $60 \mathrm{~min}$ before and during all the tests (see Figure 6). Scanning electron microscopy (SEM) characterizations were carried out on the fracture surface of representative toughness specimens using a FEI Quanta 200 microscope.

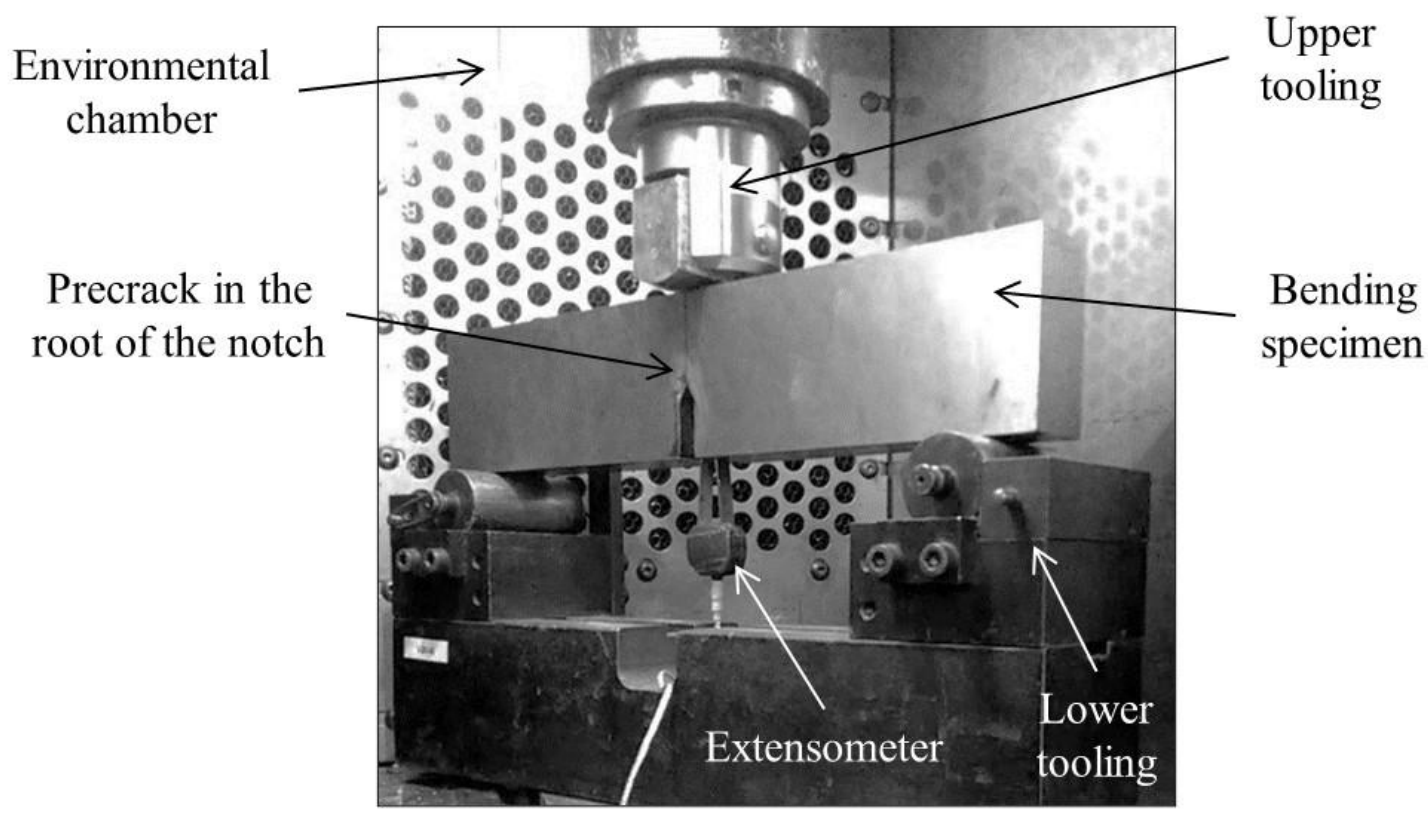

Figure 6. Testing rig employed to perform the fracture toughness tests.

Microstructure characterizations of the cast alloys were made in two steps: Firstly, samples were obtained from the bottom area of 6 randomly chosen Y2 and Y3 wedges. The analyses confirmed that all these wedges were fully pearlitic ductile iron alloys without carbides and this validated the rest of produced cast parts. In a second step, the specimens obtained from both the Y2 and Y3 wedges and from the crankshafts which were used in the tensile tests at room temperature were cut to obtain metallographic sections at $5-10 \mathrm{~mm}$ from the fractures. Quantitative image analyses were made on each sample to determine the area fraction of the graphite particles with an area equal or higher than $25 \mu^{2}$ and to assign each particle to classes III (irregular particles), V (irregular nodules) or VI (well-formed nodules). The criteria used to classify these graphite particles into classes III, V and VI are given in Table 3. The two shape parameters circularity (CR) and aspect ratio ( $\mathrm{AR}$ ) were defined as $\mathrm{CR}=4 \pi \cdot \frac{\mathrm{A}}{\mathrm{P}^{2}}$ and $\mathrm{AR}=\frac{\mathrm{L}_{\max }}{\mathrm{L}_{\min }}$ where $\mathrm{A}$ is the area of a given graphite particle, $\mathrm{P}$ is its perimeter and $\mathrm{L}_{\min }$ and $\mathrm{L}_{\max }$ are, respectively, the minimum and maximum length of the graphite particle. 
Table 3. Criteria used for classifying the graphite particles.

\begin{tabular}{|c|c|c|}
\hline Class & $\mathrm{CR}$ & $\mathrm{AR}$ \\
\hline \multirow{3}{*}{ III } & $\leq 0.70$ & $\geq 2.0$ \\
\cline { 2 - 3 } & $<0.50$ & $1.5-2.0$ \\
\cline { 2 - 3 } & $\leq 0.35$ & $1.0-1.5$ \\
\hline \multirow{3}{*}{$\mathrm{V}$} & $>0.70$ & $\geq 2.0$ \\
\cline { 2 - 3 } & $\geq 0.50$ & $1.5-2.0$ \\
\cline { 2 - 3 } & $0.35-0.77$ & $1.0-1.5$ \\
\hline VI & $\geq 0.77$ & $1.0-1.5$ \\
\hline
\end{tabular}

The obtained data were then used to determine the area fractions of graphite particles assigned to each class, namely $\mathrm{f}_{\mathrm{III}-\mathrm{A}}, \mathrm{f}_{\mathrm{V}-\mathrm{A}}$ and $\mathrm{f}_{\mathrm{VI}-\mathrm{A}}$. Nodule count $(\mathrm{Nc})$ and nodularity $(\mathrm{Nod})$ values were determined considering those graphite particles assigned to classes V and VI. Thus, Nc values were determined as the number of such particles included in $1 \mathrm{~mm}^{2}$ while nodularity values were calculated as Nod $=\left(f_{\mathrm{V}-\mathrm{A}}+f_{\mathrm{VI}-\mathrm{A}}\right) \cdot 100$. Fractions of ferrite $f_{\alpha}$ and pearlite $f_{p}$ were determined by comparing the microstructure obtained after etching with 5\% Nital with standard reference microstructures. Three different metallographic fields per sample were examined to determine the corresponding average values of each structural feature.

Those specimens used for determination of the Brinell hardness (HBW) of the cast parts were nearly cubic samples with about $10 \mathrm{~mm}$ side which were obtained from the impact specimens tested at room temperature. In this case, the testing surfaces were located $15-17 \mathrm{~mm}$ from the fracture areas. After conditioning these surfaces, hardness measurements were performed using an Instron Wolpert apparatus with a $5 \mathrm{~mm}$ diameter sphere and a load of $750 \mathrm{~kg}$.

Finally, a discussion is made in this section to justify the number of samples " $n=6$ " used in this study for a given condition, namely casting type and working temperature. This " $n$ " value should be high enough to optimize both the certainty of the statistic mean and the experimental effort needed for obtaining such data. For this purpose, it has been considered that the optimal " $n$ " value is the one in which the relative cost of increasing the sample size by one unit is higher than the relative improvement achieved in statistical reliability. The selection of the population size has been made taking as a reference value the so-called Confidence Interval of 95\% (CI95), that is, the tolerance around the experimental average that is expected to contain the actual mean value of each property with a reliability of $95 \%$. Thus, the CI95 parameter can be calculated according to equation 3 :

$$
\operatorname{CI}_{5} 5_{n}= \pm \frac{t_{0.05, n-1}}{\sqrt{n}} S_{n}
$$

where " $\mathrm{t}_{0.05, \mathrm{n}-1}$ " is the Student's " $\mathrm{t}$ " for CI95, " $\mathrm{n}$ " is the number of samples (number of tests) indicated above and $S_{n}$ is the standard deviation of the dataset. From equation 3, the uncertainty improvement factor $\left(\mathrm{MI}_{\mathrm{n}}\right)$ for using " $\mathrm{n}$ " instead of "n-1"samples is calculated as follows:

$$
\mathrm{MI}_{\mathrm{n}}=100 \cdot \frac{\frac{\mathrm{t}_{0.05, \mathrm{n}-2}}{\sqrt{\mathrm{n}-1}}-\frac{\mathrm{t}_{0.05, \mathrm{n}-1}}{\sqrt{\mathrm{n}}}}{\frac{\mathrm{t}_{0.05, \mathrm{n}-1}}{\sqrt{\mathrm{n}}}}
$$

The cost increment factor $\left(\mathrm{IC}_{\mathrm{n}}\right)$ associated to increase by one the number of samples has been calculated by means of equation 5 :

$$
\mathrm{IC}_{\mathrm{n}}=100 \cdot \frac{1}{\mathrm{n}-1}
$$




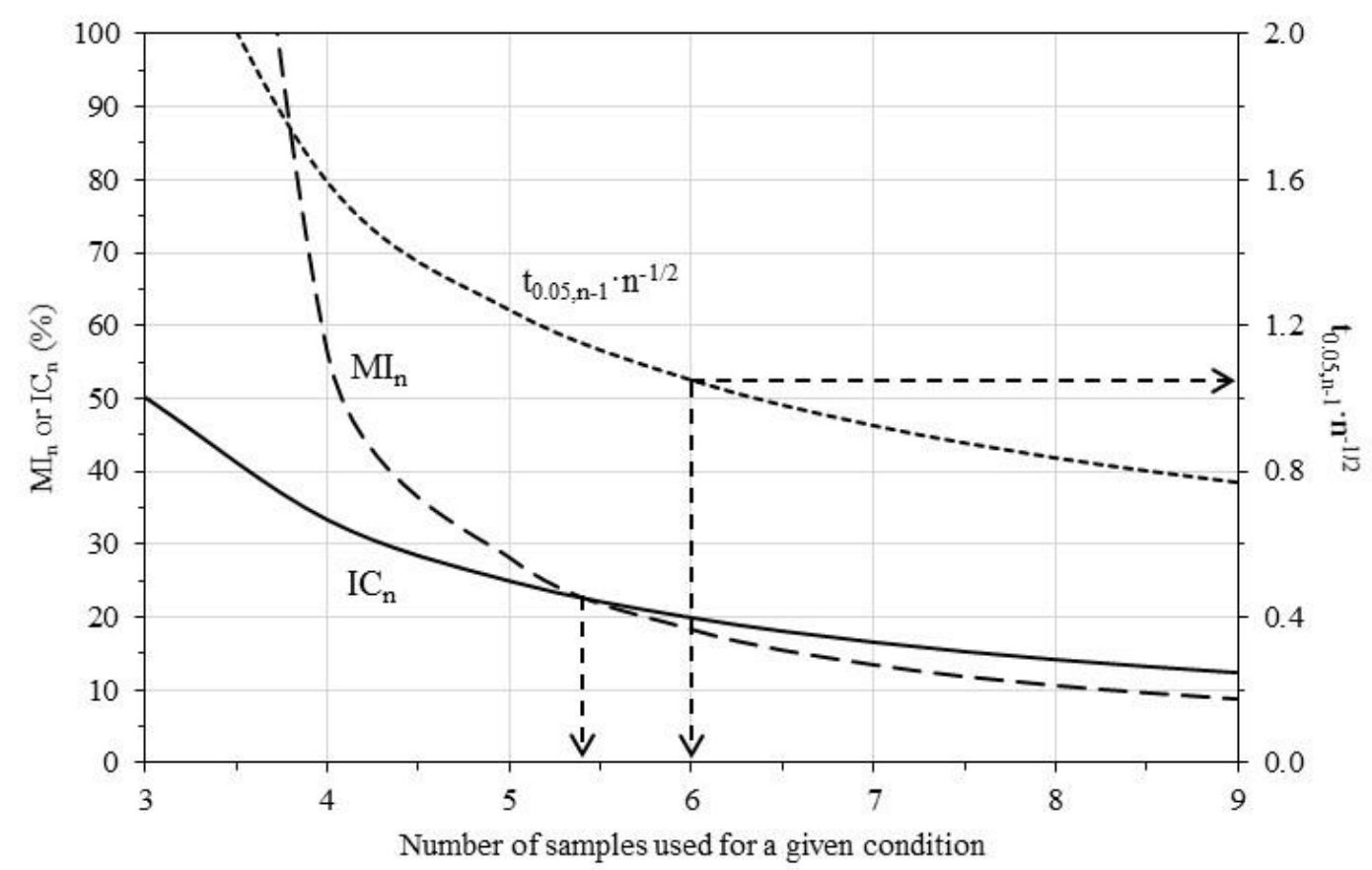

Figure 7. Evolution of $\mathrm{MI}_{\mathrm{n}}, \mathrm{IC}_{\mathrm{n}}$ and the $\mathrm{t}_{0.05, \mathrm{n}-1} \cdot \mathrm{n}^{-1 / 2}$ quantity with the number of samples.

Figure 7 has been built from equations 4 and 5 and it shows the change of $\mathrm{MI}_{\mathrm{n}}$ and $\mathrm{IC}_{\mathrm{n}}$ parameters and of the $t_{0.05, n-1} \cdot n^{-1 / 2}$ quantity with the number " $n$ " of samples. Despite uncertainty improvement and cost factor curves cross each other at 5.4 value and 5 samples would have been a good choice, when $\mathrm{n}=6$ the value $\frac{t_{0.05,5}}{\sqrt{6}}$ becomes 1.05 , what is very convenient to calculate CI95, since it allows using the standard deviation $\left(S_{\mathrm{n}=6}\right)$ directly as CI95 according to equation 6:

$$
\mathrm{CI}_{\mathrm{n}=6}= \pm \frac{\mathrm{t}_{0.05,5}}{\sqrt{6}} \mathrm{~S}_{\mathrm{n}=6}= \pm 1.05 \cdot \mathrm{S}_{\mathrm{n}=6} \approx \pm \mathrm{S}_{\mathrm{n}=6}
$$

\section{RESULTS}

\subsection{Microstructure analysis}

Although a primary verification of some Y2 and Y3 wedges was made to check their fully pearlitic structures and to validate the produced castings, a detailed characterization of the microstructure in the tested specimens has been performed to correlate with mechanical properties of the castings. For this purpose, metallographic samples were obtained from the tensile specimens tested at $22^{\circ} \mathrm{C}$ leading to the results shown in Table 4. In all cases, nodularity values are higher than $93 \%$ and microstructures are fully pearlitic with traces of ferrite in some samples obtained from the crankshafts and the Y3 wedges. From the change in Nc, it is seen that the Y2 wedges had the highest cooling rate during solidification, followed by the crankshafts and finally the Y3 wedges. Notice that one of the crankshafts was manufactured being located beside the Y3 wedge while the other one was in the external side of the mold (see Figure 4). Similarly, two of the four Y2 wedges were positioned near the Y3 one while the other two were in the external side of the mold. These characteristics affected the solidification rate and are considered as the main cause of the variability found in the Nc values for both Y2 wedges and crankshafts. As a matter of fact, variability of the Nc data of the Y3 wedges in Table 4 is comparatively low. 
Table 4. Microstructure data of the tensile specimens (Y2 and Y3 wedges and crankshafts).

\begin{tabular}{|c|c|c|c|c|c|c|c|c|}
\hline Casting & Sample & Nod (\%) & $\mathrm{Nc}\left(\mathrm{mm}^{-2}\right)$ & $f_{\text {III-A }}$ & $f_{V-A}$ & $\mathrm{f}_{\mathrm{VI}-\mathrm{A}}$ & $f_{\alpha}$ & $f_{p}$ \\
\hline \multirow{6}{*}{ 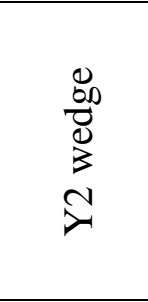 } & 1 & 97.9 & 224.1 & 0.02 & 0.16 & 0.82 & 0.00 & 1.00 \\
\hline & 2 & 96.1 & 168.2 & 0.02 & 0.40 & 0.58 & 0.00 & 1.00 \\
\hline & 3 & 98.5 & 203.9 & 0.01 & 0.18 & 0.81 & 0.00 & 1.00 \\
\hline & 4 & 96.4 & 188.0 & 0.04 & 0.19 & 0.77 & 0.00 & 1.00 \\
\hline & 5 & 97.9 & 228.5 & 0.01 & 0.16 & 0.83 & 0.00 & 1.00 \\
\hline & 6 & 97.3 & 251.9 & 0.02 & 0.15 & 0.83 & 0.00 & 1.00 \\
\hline \multirow{6}{*}{$\begin{array}{l}8 \\
\frac{8}{8} \\
0 \\
3 \\
2\end{array}$} & 1 & 96.3 & 96.0 & 0.01 & 0.36 & 0.63 & Traces & 1.00 \\
\hline & 2 & 95.3 & 101.7 & 0.01 & 0.45 & 0.54 & Traces & 1.00 \\
\hline & 3 & 98.4 & 94.2 & 0.00 & 0.34 & 0.66 & Traces & 1.00 \\
\hline & 4 & 100 & 96.4 & 0.00 & 0.34 & 0.66 & 0.00 & 1.00 \\
\hline & 5 & 98.7 & 103.0 & 0.00 & 0.34 & 0.66 & Traces & 1.00 \\
\hline & 6 & 97.5 & 96.0 & 0.01 & 0.44 & 0.55 & Traces & 1.00 \\
\hline \multirow{6}{*}{ 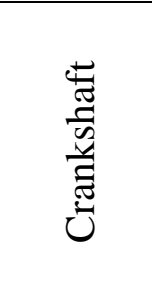 } & 1 & 94.3 & 166.4 & 0.04 & 0.37 & 0.59 & Traces & 1.00 \\
\hline & 2 & 93.2 & 166.0 & 0.06 & 0.27 & 0.67 & 0.00 & 1.00 \\
\hline & 3 & 97.5 & 192.0 & 0.02 & 0.31 & 0.67 & 0.00 & 1.00 \\
\hline & 4 & 93.1 & 171.7 & 0.05 & 0.24 & 0.71 & 0.00 & 1.00 \\
\hline & 5 & 96.4 & 186.3 & 0.03 & 0.26 & 0.71 & Traces & 1.00 \\
\hline & 6 & 95.4 & 164.7 & 0.04 & 0.43 & 0.53 & Traces & 1.00 \\
\hline
\end{tabular}

Although all wedges and crankshafts could be considered as having fully pearlitic microstructures, traces of ferrite were occasionally found in the crankshafts (Figure 8a) and were frequently found in the Y3 wedges (Figure 8b), always around the graphite nodules. On the contrary, ferrite was not detected in the Y2 samples. These observations agree with the comparative solidification rates discussed above on the basis of the nodule count differences among casting types.

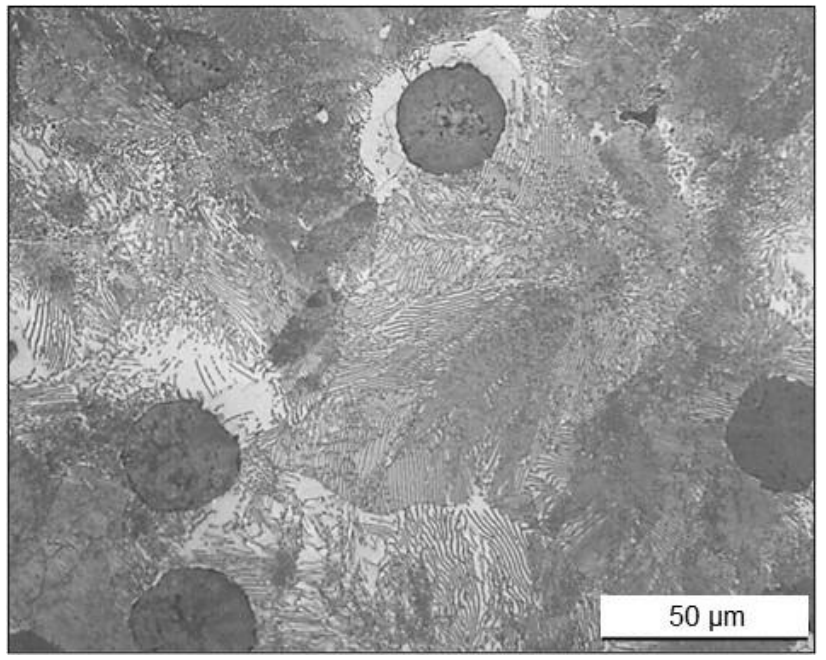

(a)

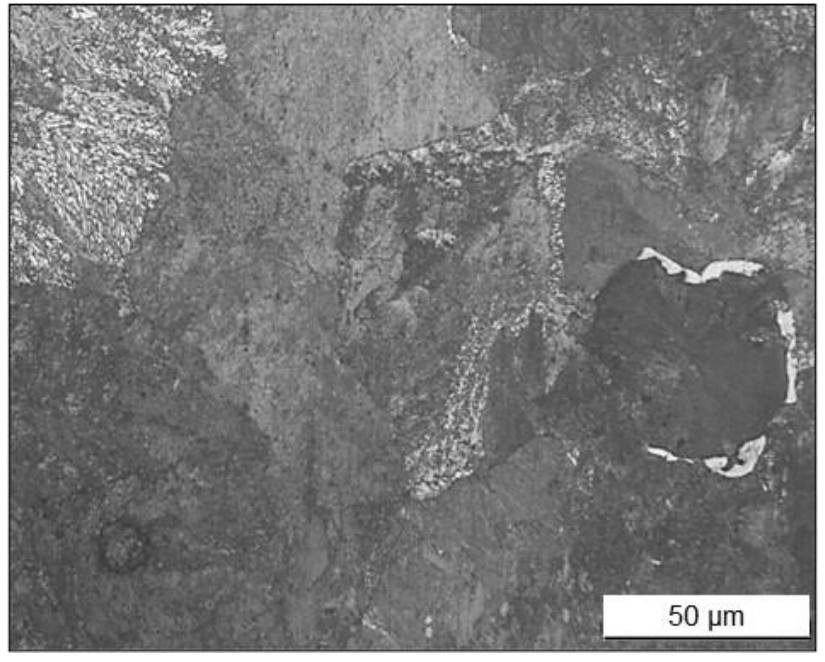

(b)

Figure 8. Traces of ferrite present in (a) crankshafts and (b) Y3 wedges.

Another relevant structural feature is the interlamellar spacing of pearlite aggregates, which was qualitatively evaluated in the 18 samples. Examples of representative pearlite lamellas in the samples obtained from the Y2 wedges and from the crankshafts are compared in Figure 9. It is seen that the interlamellar spacing appears smaller in the former case than in the latter, supporting again the correlation of the cooling rate estimates based on the Nc values. 


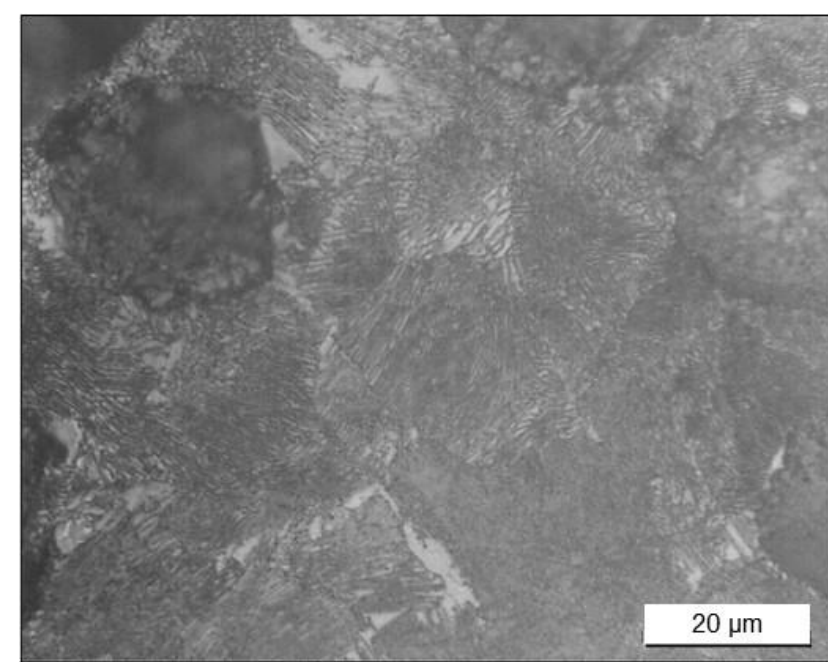

(a)

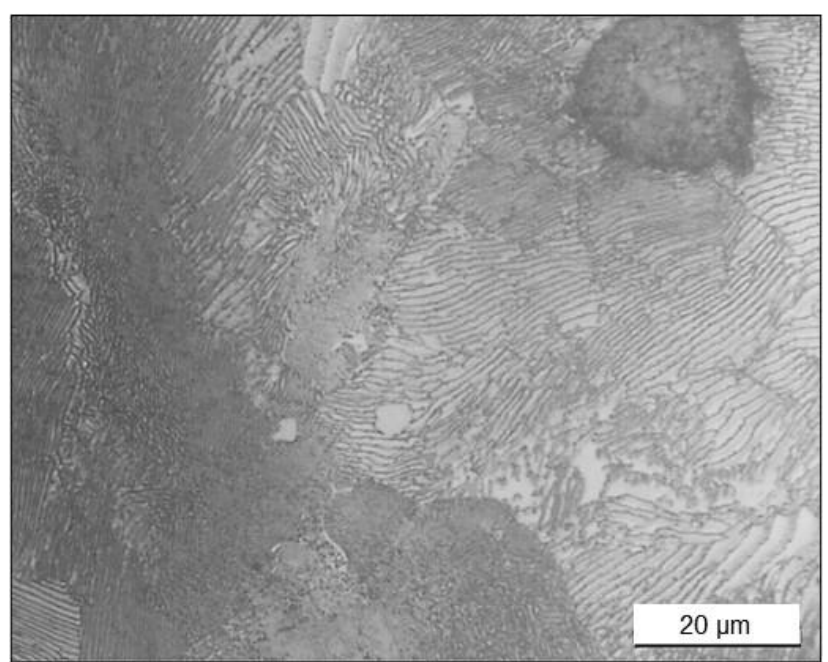

(b)

Figure 9. Detailed view of the interlamellar spacing of pearlite in: (a) Y2 wedges and (b) crankshafts.

Unexpectedly, analogous inspection on pearlite aggregates of the Y3 wedges showed that the interlamellar spacing is quite similar to the one observed in the Y2 castings (see Figures $8 \mathrm{~b}$ and 9a) being finer in both wedge types than in the crankshafts (Figure 9b). This result was confirmed in all 6 samples obtained from the Y3 wedges despite these castings have the heaviest size and the comparison of other structural feature like Nc indicates a low solidification rate. Thus, a possible explanation for this unexpected observation is the time elapsed between pouring the molds and the demolding process. It seems evident that solidification rate was the lowest in case of the Y3 wedges, however a rapid cooling just before the eutectoid transition of these castings provoked by an early demolding step would explain the structural finding. The traces of ferrite that have been mentioned must have appeared slightly before the shake out, at a temperature higher than $650^{\circ} \mathrm{C}$. Thus, a schematic of the cooling rates expected on the three casting types according to the Nc and pearlite interlamellar spacing results is given in Figure 10.

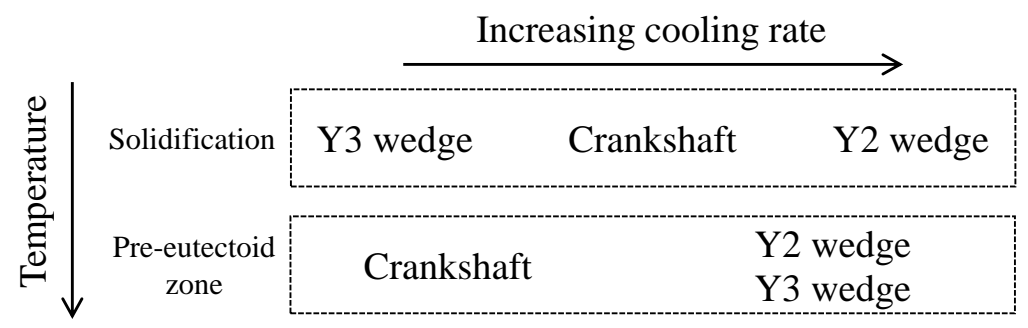

Figure 10. Comparative cooling rates of the three castings used in this work according to the microstructure results.

\subsection{Brinell hardness}

Table 5 lists the results obtained from all hardness tests, as well as the average value and the standard deviation $\left(S_{n}=6\right)$ for each cast part. The hardness values show some heterogeneity for a given cast part, and it is seen that the mean values obtained from the Y3 and Y2 wedges are similar and are significantly higher than those obtained for the crankshafts.

Compared to Y3 wedges, hardness variability among the Y2 wedge samples or the crankshafts is due to the effect of different cooling rates of the different cavities present in the pattern plate as described above (Figure 4). Nevertheless, the changes in hardness observed in Table 5 when comparing the three castings can be explained in terms of pearlite interlamellar spacing as described in section 3.1. Thus, the Y3 wedges samples led to high hardness values even with traces of ferrite 
as the pearlite aggregates present in this casting showed comparatively a quite low interlamellar spacing. On the other hand, high hardness values were also found in the Y2 samples where ferrite was not detected and the interlamellar spacing was small. Notice that values from the Y2 samples in Table 5 are slightly lower than those from the Y3 ones which denotes that pearlite aggregates could contain the lowest interlamellar spacing in these heaviest castings. This is supported by the already mentioned effect of an early demolding on the eutectoid reaction in the Y3 wedges. Finally, the samples obtained from the crankshafts showed the lowest hardness values because of the higher interlamellar spacing of pearlite.

Table 5. HBW results obtained at room temperature $\left(22^{\circ} \mathrm{C}\right)$.

\begin{tabular}{|c|c|c|c|}
\hline Sample & Y2 wedge & Y3 wedge & Crankshaft \\
\hline 1 & 298 & 301 & 268 \\
\hline 2 & 282 & 311 & 274 \\
\hline 3 & 295 & 309 & 276 \\
\hline 4 & 288 & 307 & 275 \\
\hline 5 & 300 & 303 & 258 \\
\hline 6 & 304 & 311 & 267 \\
\hline Average & 295 & 307 & 270 \\
\hline $\mathrm{S}_{\mathrm{n}=6}$ & 8 & 4 & 7 \\
\hline
\end{tabular}

Data from Tables 1, 4 and 5 were used here to quantitatively estimate the average cooling rate values into the range $1050-715^{\circ} \mathrm{C}\left(\mathrm{V}_{\mathrm{r}}\right)$ for the sampling areas of the castings. This parameter represents the cooling rate just before austenite transforms to pearlite by the eutectoid reaction and it has been evaluated by using the relationship reported by Serrallach et al. [13]. These authors obtained equations by statistical analyses relating composition data, cooling rates, hardness and tensile data from 85 pearlitic ductile cast irons. In the present case the reverse calculation has been made and the obtained $\mathrm{Vr}$ values have been used to check the cooling trends suggested in Figure 10. Thus the calculated cooling rate values are: $10.3 \mathrm{~K} \cdot \mathrm{min}^{-1}, 32.0 \mathrm{~K} \cdot \mathrm{min}^{-1}$ and $34.8 \mathrm{~K} \cdot \mathrm{min}^{-1}$ for the crankshafts, the Y2 wedges and the Y3 wedges, respectively. In the following section, these results will be discussed together with the $\mathrm{Vr}$ values calculated with the tensile tests findings and compared to the expectations shown in Figure 10.

\subsection{Tensile tests}

Regarding the tensile properties of the alloys, Table 6 shows the average values and the standard deviations of UTS, YS and A at the three working temperatures considered in the present study. The UTS and YS data have been also plotted in Figure 11 to facilitate the interpretation of the results. As expected, an increase of the testing temperature reduces both UTS and YS, while an increment of $\mathrm{A}$ is observed since the material increases its ductility (Table 6). Notice that UTS and YS always remain above $900 \mathrm{MPa}$ and $550 \mathrm{MPa}$ thresholds, respectively, for the two wedges while these parameters are reduced by about $100 \mathrm{MPa}$ in the case of the crankshafts. Comparatively, it is also remarkable that the tensile strength shows a lower decrease $(\approx 4 \%)$ than the yield strength $(\approx 12 \%)$ between $-20^{\circ} \mathrm{C}$ and $120^{\circ} \mathrm{C}$. This result is observed for all three casting types and it indicates that the material maintains its overall strength during the tensile test though it begins to flow at slightly lower loads as the working temperature increases.

The use of a graphical representation of the results is also of help when comparing the strength results obtained from the three types of castings (Figure 11). The specimens from the Y2 and Y3 wedges showed the highest UTS and YS values which will be correlated later with trends 
previously described for microstructure and hardness. The fact that Y2 wedges exhibit UTS and YS results with an evolution which parallels that of the crankshafts implies that the Y2 wedges can be used as a valuable reference for quality control in foundry plants.

Table 6. Main statistical descriptors for the tensile tests at the three working temperatures.

\begin{tabular}{|c|c|c|c|c|c|c|c|}
\hline \multirow{2}{*}{ Casting } & \multirow{2}{*}{$\mathrm{T}\left({ }^{\circ} \mathrm{C}\right)$} & \multicolumn{2}{|c|}{ UTS $(\mathrm{MPa})$} & \multicolumn{2}{c|}{ YS $(\mathrm{MPa})$} & \multicolumn{2}{c|}{$\mathrm{A}(\%)$} \\
\cline { 3 - 8 } & & Average & $\mathrm{S}_{\mathrm{n}=6}$ & Average & $\mathrm{S}_{\mathrm{n}=6}$ & Average & $\mathrm{S}_{\mathrm{n}=6}$ \\
\hline \multirow{3}{*}{ Y2 wedge } & -20 & 963 & 12 & 652 & 9 & 2.5 & 0.5 \\
\cline { 2 - 8 } & 22 & 969 & 16 & 598 & 6 & 4.2 & 0.3 \\
\cline { 2 - 8 } & 120 & 922 & 7 & 572 & 9 & 4.2 & 0.5 \\
\hline \multirow{3}{*}{ Y3 wedge } & -20 & 983 & 20 & 675 & 14 & 3.2 & 0.5 \\
\cline { 2 - 8 } & 22 & 959 & 8 & 610 & 13 & 4.3 & 0.5 \\
\cline { 2 - 8 } & 120 & 944 & 9 & 591 & 5 & 5.4 & 0.2 \\
\hline \multirow{3}{*}{ Crankshaft } & -20 & 856 & 15 & 573 & 7 & 3.1 & 0.3 \\
\cline { 2 - 8 } & 22 & 870 & 7 & 529 & 9 & 4.7 & 0.3 \\
\cline { 2 - 8 } & 120 & 839 & 6 & 497 & 7 & 4.6 & 0.3 \\
\hline
\end{tabular}

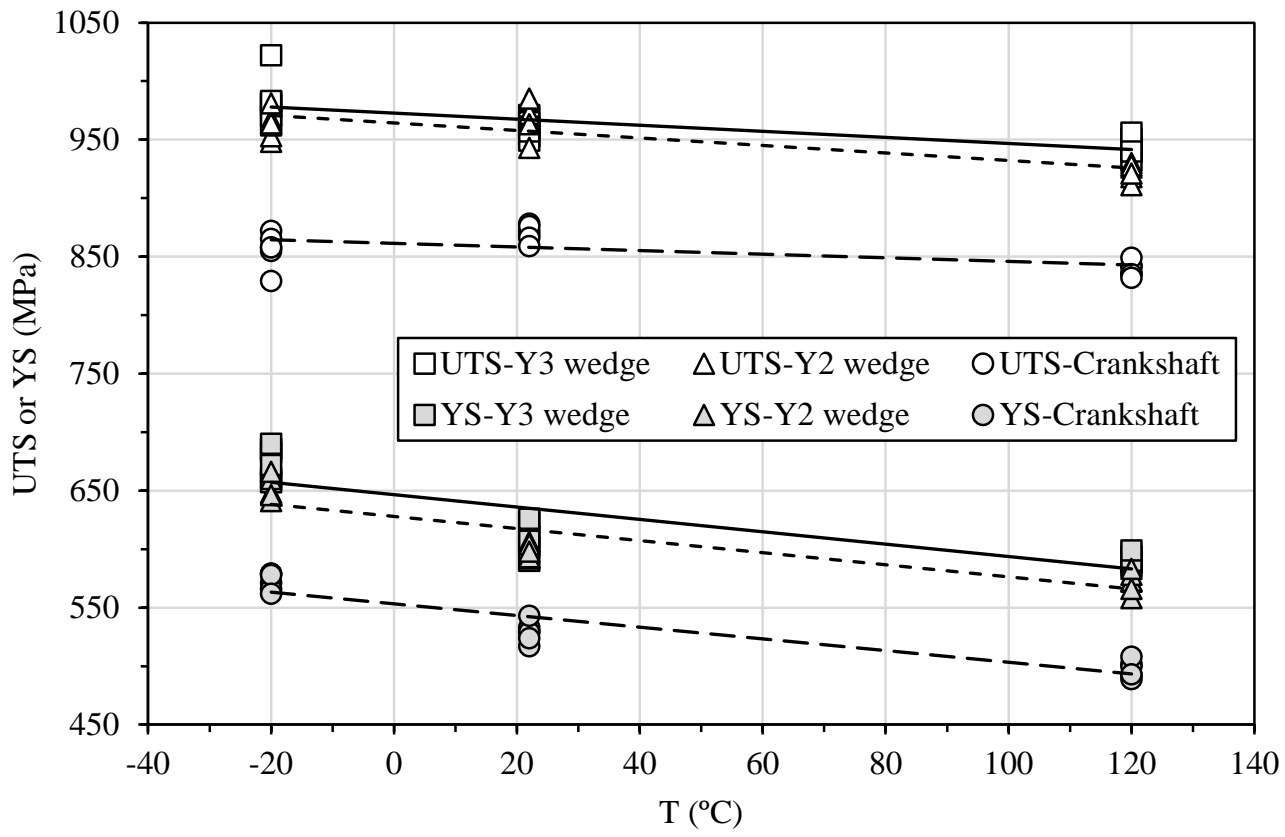

Figure 11. Evolution of UTS and YS with temperature for the three casting types.

Notice that the average UTS and YS values obtained at $22^{\circ} \mathrm{C}$ from the crankshafts are about 870 $\mathrm{MPa}$ and $530 \mathrm{MPa}$, respectively. It should be considered that these values were obtained from the diagonal areas highlighted in Figure 2 which likely underwent the lowest cooling rate among the different areas of this casting. In order to further explore the effect of the cooling rate on the tensile properties of the crankshafts, four additional tensile specimens $5 \mathrm{~mm}$ in diameter were machined out from the counterweights where cooling rates are expected to be the fastest for this casting. The results obtained from these tests performed at $22^{\circ} \mathrm{C}$ were UTS $=956-982 \mathrm{MPa}, \mathrm{YS}=593-622 \mathrm{MPa}$ and $\mathrm{A}=4.0-4.9 \%$ which are similar to the average values reported in Table 6 for the Y2 and Y3 wedges. The microstructures found in the counterweights were fully pearlitic with interlamellar spacing smaller than that observed in the diagonal areas. 
As it has been already observed in the microstructural and hardness characterizations, the UTS and YS values in Table 6 also suggested that the tested areas of the crankshafts experienced the lowest cooling rate in the eutectoid zone when comparing to the wedges. This fact appears related to the highest interlamellar spacing of pearlite aggregates in the specimens obtained from the crankshafts. However, the most remarkable result is the similar UTS and YS values obtained at the three temperatures tested for the Y2 and Y3 wedges (see Figure 11) despite their different size. This result indicates that the similar interlamellar spacing of pearlite aggregates present in these two castings strongly affected these two parameters rendering a minor role to the ferrite traces detected in the Y3 specimens.

Figure 12 shows the evolution of elongation at rupture with temperature for the three different casting types. The corresponding scatter bands, determined as the range $[\mathrm{A}] \pm \mathrm{t}_{0.05,5} \cdot \frac{\mathrm{S}_{\mathrm{n}=6}}{\sqrt{6}}$, where $[\mathrm{A}]$ corresponds to the average elongation value, are also plotted in this figure and they represent $95 \%$ confidence interval of the average values. The elongation at rupture of all three casting types drops at $-20^{\circ} \mathrm{C}$, the values obtained at $22^{\circ} \mathrm{C}$ and $120^{\circ} \mathrm{C}$ being similar to each other in case of the specimens obtained from the $\mathrm{Y} 2$ wedges and the crankshaft. A relevant increase of elongation at the highest temperature is found in case of the Y3 wedges which could be due to the effect of ferrite traces surrounding some of the graphite nodules and/or to the comparatively low Nc values found in this heavy casting. As the small ferrite contents did not show any significant effect on UTS and YS in the Y3 wedges, it can be concluded that the effect of nodule count is predominant over the influence of ferrite contents.

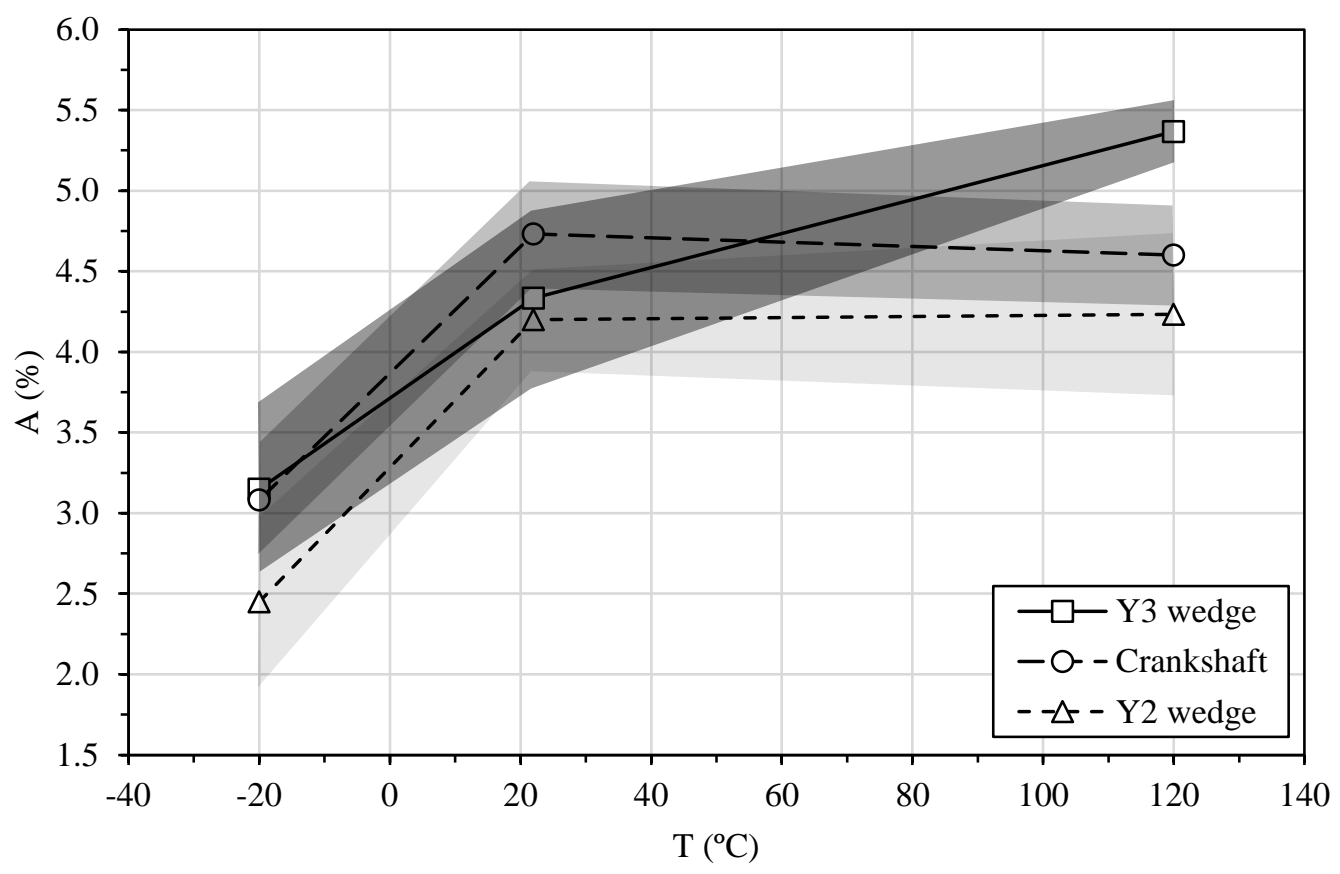

Figure 12. Effect of temperature on the average values of elongation at rupture. The greyed areas represent the $95 \%$ confidence intervals (see text).

To visualize the effect of Nc on A, these two parameters have been plotted in Figure 13 for each testing temperature and casting type. No influence of $\mathrm{Nc}$ on elongation is observed at $22^{\circ} \mathrm{C}$ while elongation decreases in those specimens with increased nodule count in a clear way at $120^{\circ} \mathrm{C}$. A similar trend is observed at $-20^{\circ} \mathrm{C}$ though it is weak and scattered. A values from the $\mathrm{Y} 3$ wedges are higher than those from the Y2 wedges at these two temperatures, suggesting that low Nc values are beneficial as the pearlite interlamellar spacing is similar in these two wedges. In case of the crankshafts, elongation values are scattered and slightly lower than those from the Y2 wedges 
despite they showed the highest interlamellar spacing. These observations suggest again that Nc has a predominant effect on $\mathrm{A}$.

It is also worthy to note that the evolutions of UTS, YS and A shown in Figures 11-13 for a given casting geometry at $120^{\circ} \mathrm{C}$ do not show the usual behavior of decreasing elongation with increasing UTS and YS. More precisely, the Y3 wedges exhibited the highest average UTS, YS and A values at $120^{\circ} \mathrm{C}$ as pearlite interlamellar spacing and $\mathrm{Nc}$ are comparatively low. These findings suggest that the effect of interlamellar spacing is dominant on ultimate tensile and yield strengths while nodule count mainly affects elongation in these fully pearlitic cast irons. This effect seems to be mainly related to the resistant metallic sections (mean-free distance) in between nodules which are larger when decreasing nodule count.

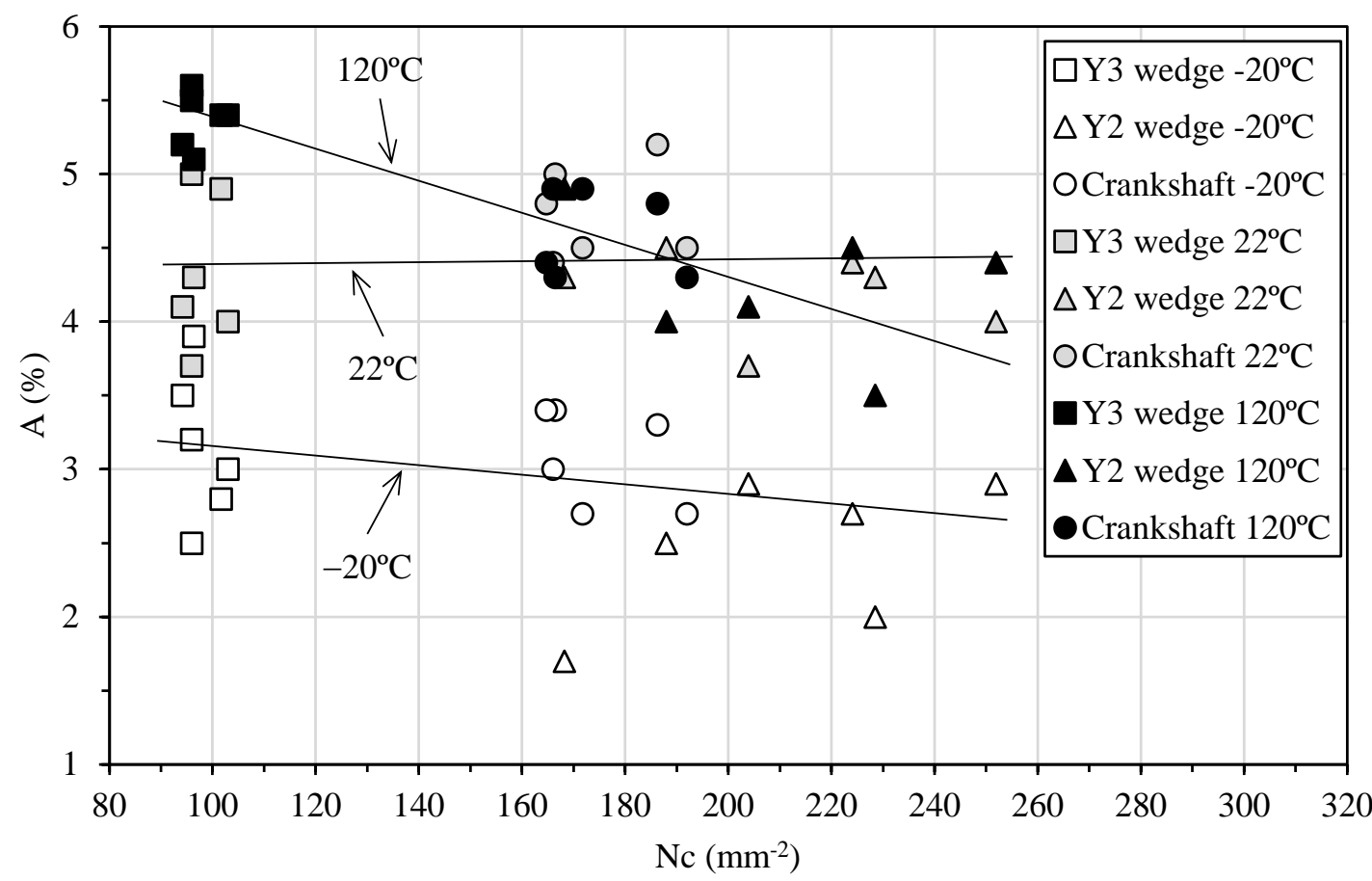

Figure 13. Evolution of elongation at rupture with Nc.

Data included in Tables 1, 4 and 6 have been used to estimate the $V_{r}$ parameter (see section 3.2) in the areas from which tensile specimens were obtained according to the expressions reported by Serrallach et al. [13]. All the calculated values are compared in Table 7 including the data from hardness results (section 3.2). Although these data appear with some scattering, the highest $\mathrm{Vr}$ values are obtained for the Y3 and Y2 wedges while the lowest ones correspond to the crankshafts. These results agree with the expectations shown in Figure 10 which are based on the microstructure observations.

Table 7. Estimated $\mathrm{V}_{\mathrm{r}}$ values $\left(\mathrm{K} \cdot \mathrm{min}^{-1}\right)$ according to tensile results at $22^{\circ} \mathrm{C}$ and to the equation reported by Serrallach et al. [13].

\begin{tabular}{|c|c|c|c|}
\hline Property & Y2 wedges & Y3 wedges & Crankshafts \\
\hline HBW & 32.0 & 34.8 & 10.3 \\
\hline UTS & 48.7 & 44.0 & 12.5 \\
\hline YS & 41.9 & 46.8 & 19.0 \\
\hline
\end{tabular}




\subsection{Impact tests}

It is observed in Table 8 that impact values show low variability with low standard deviation values regardless of the type of casting and of the testing temperature. The basic statistical descriptors in Table 8 show that the impact test does not present any change allowing to discriminate the effect of the variables used in the study. The produced material is too sensitive to the notch effect and it is not possible to detect differences in the absorbed energy as usually found in cast iron grades as stated by Wallin [15]. This makes the use of $\mathrm{K}_{\mathrm{IC}}$ specimens recommendable to show relevant differences between two testing or material conditions, as it was shown with ADI grades by Artola et al. [16]. Thus, more advanced experimental techniques, such as the ASTM E399 method, have been selected to characterize the toughness of the crankshafts.

Table 8. Average impact values $\left(\mathrm{J} \cdot \mathrm{cm}^{-2}\right)$ and standard deviation at the three working temperatures.

\begin{tabular}{|c|c|c|c|}
\hline Casting & $\mathrm{T}\left({ }^{\circ} \mathrm{C}\right)$ & Average & $\mathrm{S}_{\mathrm{n}=6}$ \\
\hline \multirow{3}{*}{ Y2 wedge } & -20 & 3.0 & 0.0 \\
\cline { 2 - 4 } & 22 & 3.0 & 0.0 \\
\cline { 2 - 4 } & 120 & 4.8 & 0.4 \\
\hline \multirow{3}{*}{ Y3 wedge } & -20 & 3.8 & 0.4 \\
\cline { 2 - 4 } & 22 & 4.0 & 0.6 \\
\cline { 2 - 4 } & 120 & 5.0 & 0.0 \\
\hline \multirow{3}{*}{ Crankshaft } & -20 & 3.0 & 0.0 \\
\cline { 2 - 4 } & 22 & 3.8 & 0.4 \\
\cline { 2 - 4 } & 120 & 4.0 & 0.0 \\
\hline
\end{tabular}

\subsection{Fracture toughness}

All the $\mathrm{K}_{\mathrm{IC}}$ toughness results obtained from the $\mathrm{Y} 3$ wedges are listed in Table 9 and their average values with the scatter band defined by the range $\left[\mathrm{K}_{\mathrm{IC}}\right] \pm \mathrm{t}_{0.05,5} \cdot \frac{\mathrm{S}_{\mathrm{n}=6}}{\sqrt{6}}$ are plotted in Figure 14 . The effect of the temperature on the material toughness can be clearly assessed, what was not feasible with impact test specimens. It is observed that there is a significant increase of the toughness with the temperature, which almost doubles from $-20^{\circ} \mathrm{C}$ to $120^{\circ} \mathrm{C}$. Tensile tests had also shown an increase in elongation with temperature raise.

Table 9. Fracture toughness testing results on the Y3 wedges at different temperatures.

\begin{tabular}{|c|c|c|c|c|c|c|c|c|}
\hline $\begin{array}{c}\mathrm{T} \\
\left({ }^{\circ} \mathrm{C}\right)\end{array}$ & Sample & $\begin{array}{c}\mathrm{K}_{\mathrm{IC}} \\
\left(\mathrm{MPa} \cdot \mathrm{m}^{1 / 2}\right)\end{array}$ & $\begin{array}{c}\mathrm{T} \\
\left({ }^{\circ} \mathrm{C}\right)\end{array}$ & Sample & $\begin{array}{c}\mathrm{K}_{\mathrm{IC}} \\
\left(\mathrm{MPa} \cdot \mathrm{m}^{1 / 2}\right)\end{array}$ & $\begin{array}{c}\mathrm{T} \\
\left({ }^{\circ} \mathrm{C}\right)\end{array}$ & Sample & $\begin{array}{c}\mathrm{K}_{\mathrm{IC}} \\
\left(\mathrm{MPa} \cdot \mathrm{m}^{1 / 2}\right)\end{array}$ \\
\hline \multirow{8}{*}{-20} & 1 & 32.4 & \multirow{8}{*}{22} & 1 & 43.9 & \multirow{8}{*}{120} & 1 & 58.3 \\
\hline & 2 & 30.5 & & 2 & 40.8 & & 2 & 54.4 \\
\hline & 3 & 34.6 & & 3 & 46.4 & & 3 & 52.2 \\
\hline & 4 & 38.1 & & 4 & 43.8 & & 4 & 56.3 \\
\hline & 5 & 36.2 & & 5 & 44.6 & & 5 & 55.5 \\
\hline & 6 & 33.0 & & 6 & 45.3 & & 6 & 54.9 \\
\hline & Average & 34.1 & & Average & 44.1 & & Average & 55.3 \\
\hline & $S_{n=6}$ & 2.7 & & $S_{n}=6$ & 1.9 & & $S_{n=6}$ & 2.0 \\
\hline
\end{tabular}




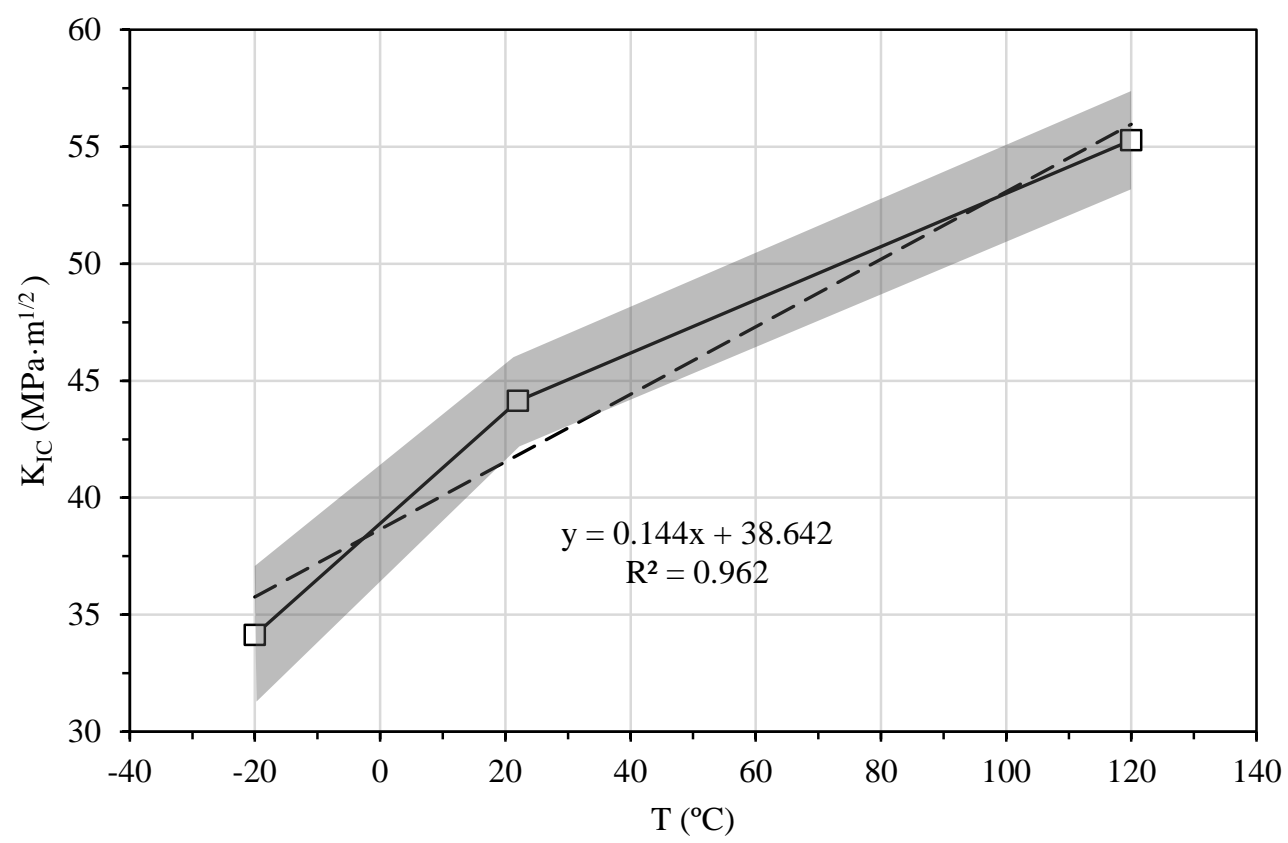

Figure 14. Effect of temperature on the average $\mathrm{K}_{\mathrm{IC}}$ values for $40 \mathrm{~mm}$ thickness specimens extracted from Y3 wedges. The dashed line shows the least-square linear regression on the average values.

Regardless of the testing temperature, fracture surfaces showed a cleavage-like morphology confirming the $\mathrm{K}_{\mathrm{IC}}$ driven behavior of the material for the tested thickness. Figure 15a is a representative micrograph of the brittle surfaces in one of the toughness specimens at $22^{\circ} \mathrm{C}$ where the usual cleavage areas are widespread across the fracture. This brittle behavior has been also detected mixed with the conventional fatigue texture in the controlled pre-crack growth surface, as pointed out in Figure $15 \mathrm{~b}$ by white arrows. This suggests that brittle behavior was also involved in the fatigue pre-crack generation.

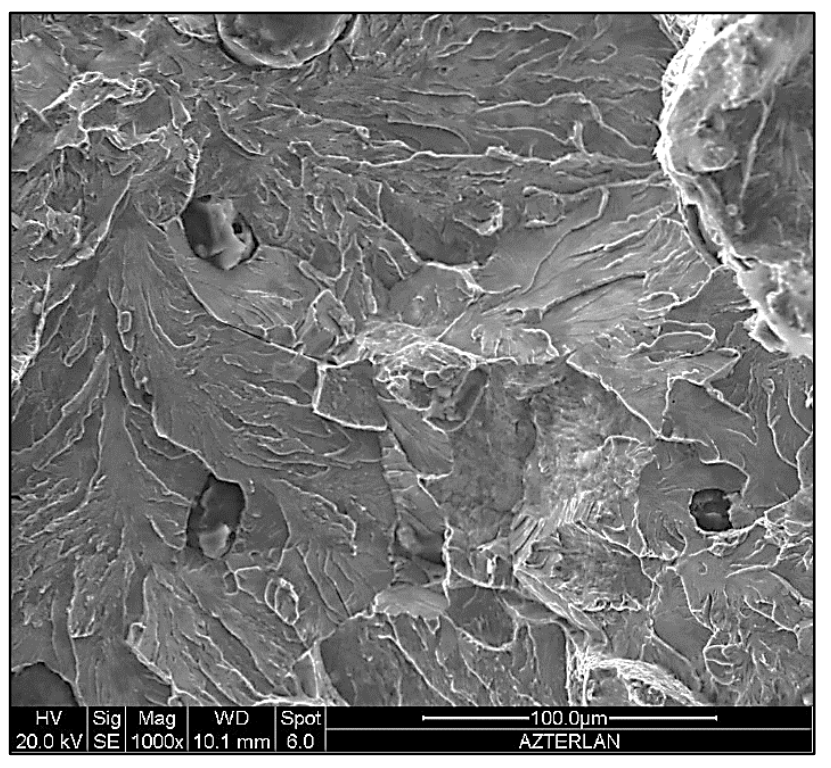

(a)

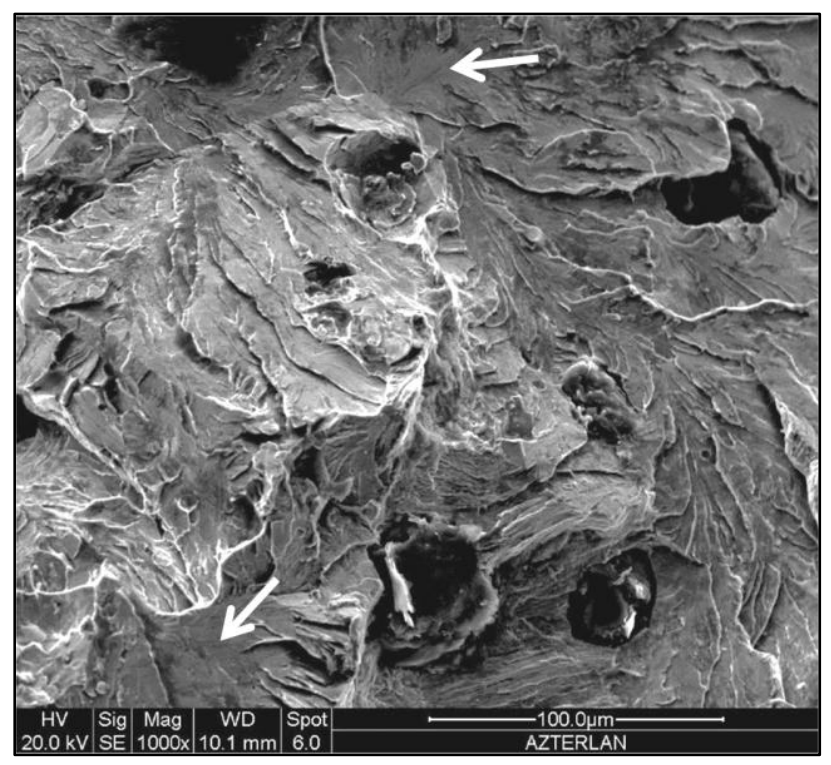

(b)

Figure 15. Representative crack surface textures for the controlled brittle fracture area (a) and the fatigue crack growth area (b) of the toughness specimens from Y3 wedges. 


\section{DISCUSSION}

For the fracture toughness test to be valid, plain strain condition should be ensured that needs the following condition to be satisfied:

$$
\mathrm{B} \geq 2.5\left(\frac{\mathrm{K}_{\mathrm{IQ}}}{\mathrm{YS}}\right)^{2}
$$

With the values found, the choice of a thickness $B=40 \mathrm{~mm}$ for the toughness test specimens has been appropriate since the crack tip was under plane strain. This condition implies that the fracture mechanism has followed linear elastic fracture mechanics in the present case. On the contrary, if 20 $\mathrm{mm}$ thick specimens had been chosen, the plain strain condition imposed by equation 7 would not have been fulfilled for the tests at $120^{\circ} \mathrm{C}$, meaning that the result would have not been representative of the bearing journal of the crankshaft fracture mechanics [14].

When translating the toughness test results to design decisions, it must be considered that in most cases the crankshaft is at room temperature when the engine starts, and the regular working temperature for steady state condition is $90^{\circ} \mathrm{C}$. The least-square linear regression fit to the data in Figure 13 shows a slope of 0.144 . This means that the toughness increases by $9.1 \mathrm{MPa} \cdot \mathrm{m}^{1 / 2}$ from cold start, at $25^{\circ} \mathrm{C}$, to stable engine regime, at $90^{\circ} \mathrm{C}$. Taking the stress intensity factors for a forged steel crankshaft modeled in [17] as an example, $1.5 \mathrm{~mm}$ and $2.5 \mathrm{~mm}$ cracks cause stress intensity factors of $40 \mathrm{MPa} \cdot \mathrm{m}^{1 / 2}$ and $50 \mathrm{MPa} \cdot \mathrm{m}^{1 / 2}$ respectively. Thus, if a crankshaft after the design from [17] and manufactured in the material studied in this work stands a cold engine start while having a $1.5 \mathrm{~mm}$ crack, it should not break until the crack grows up to $2.5 \mathrm{~mm}$. Hypothesizing an engine speed of $2000 \mathrm{rpm}$, a peak fatigue cycle each 4 turns (significant only during the expansion cycle) and a torque ratio of 0.1 from start to average running condition [18], an estimated crack growth rate of $10^{-3} \mathrm{~mm} / \mathrm{min}[19,20]$ would lead to $16 \mathrm{~h}$ of driving until fracture, what turns out far longer than the time between refueling stops. Thus, crankshaft fracture risk during driving, after oil warmup is greatly reduced by the temperature effect on toughness. This advantage is further improved if the cold start temperature of the engine is below zero, for example at $-10^{\circ} \mathrm{C}$. The linear regression obtained in Figure 14 gives a $\mathrm{K}_{\mathrm{IC}}$ value of $37 \mathrm{MPa} \cdot \mathrm{m}^{1 / 2}$ for this condition, which leads to a critical crack size of $1.3 \mathrm{~mm}$ considering the same crankshaft geometry as above [17]. If the same crack growth rate as before is assumed $\left(10^{-3} \mathrm{~mm} / \mathrm{min}\right)$, the time to fracture would increase to $19 \mathrm{~h}$ of driving.

It is worth it to recall here that the unexpected behavior found on the Y3 wedges related to their comparatively high UTS, YS and hardness values is likely due to premature demolding. If Y3 wedges would have completely undergone the eutectoid transition inside the mold, it would have led to hardness, UTS and YS values lower than those reported in Tables 5 and 6 . Thus, the fracture toughness response of such an alloy would be expected to show $\mathrm{K}_{\mathrm{IC}}$ values higher than the expected ones for the Y3 wedges produced in the present work, with these latter castings representing the most critical test condition between these two cooling possibilities. As a consequence, longer safe driving times could be achieved.

Not considering the intimate fracture mechanisms involved in brittle fracture (cleavage) and ductile collapse (dislocation movement), the experimental data presented in this work have been used to obtain an equation for estimating $\mathrm{K}_{\mathrm{IC}}$ by using as input variables the testing temperature values and the tensile results from specimens produced with Y2 wedges commonly used in foundry plants. Experimental determinations of $\mathrm{K}_{\mathrm{IC}}$ values at different temperatures are expensive compared to conventional tensile testing. Therefore, such an equation may be useful to assess the fracture toughness of fully pearlitic ductile irons with similar casting sizes (cooling rates) to the ones used in this study, avoiding time consuming and costly tests. 
In a first step, the correlation coefficients between $\mathrm{K}_{\mathrm{IC}}$, as the output variable, the three tensile parameters included in Table 6 (UTS, YS and A) in case of the Y2 wedges and the testing temperature (T) were determined by means of Pearson method. The coefficients thus obtained are shown in Table 10 where the sign of each of them shows the expected positive or negative correlation between each variable and $\mathrm{K}_{\mathrm{IC}}$.

Table 10. Pearson correlation coefficients referred to $\mathrm{K}_{\mathrm{IC}}$ of the tensile parameters related to the $\mathrm{Y} 2$ wedges and of the testing temperature.

\begin{tabular}{|c|c|c|c|c|}
\hline Variable referred to Y2 wedges & UTS & YS & A & T \\
\hline Pearson coefficient & -0.714 & -0.926 & 0.752 & 0.954 \\
\hline
\end{tabular}

As all Pearson coefficients were over 0.70, they are considered relevant and the four input variables from the $\mathrm{Y} 2$ wedges were used in a second step to carry out a multivariable linear regression using the 18 rows of data available and to determine $\mathrm{K}_{\mathrm{IC}}$ according to equation 8 . This analysis gave a $\mathrm{R}^{2}$ regression coefficient of 0.94 :

$$
\mathrm{K}_{\mathrm{IC}}=65.66+0.107 \cdot \mathrm{T}-0.002 \cdot \mathrm{UTS}-0.046 \cdot \mathrm{YS}+1.205 \cdot \mathrm{A}
$$

where $\mathrm{K}_{\mathrm{IC}}, \mathrm{T}$, UTS, YS and A parameters are given in $\mathrm{MPa} \cdot \mathrm{m}^{1 / 2},{ }^{\circ} \mathrm{C}, \mathrm{MPa}, \mathrm{MPa}$ and $\%$, respectively.

Figure 16 compares the experimental and calculated values of $\mathrm{K}_{\mathrm{IC}}$ at the three testing temperatures used in this work. As it has been seen in Figure 14, the highest scatter of data in Figure 16 is found at $-20^{\circ} \mathrm{C}$ with an absolute average error of $7.8 \%$. At low temperature, it is assumed that the fracture toughness of the alloy is comparatively more sensitive to the presence of inclusions and/or small porosities (pinholes or isolated microshrinkage) than at room or high temperatures. This fact is probably the cause of the higher variability of the data at low temperature.

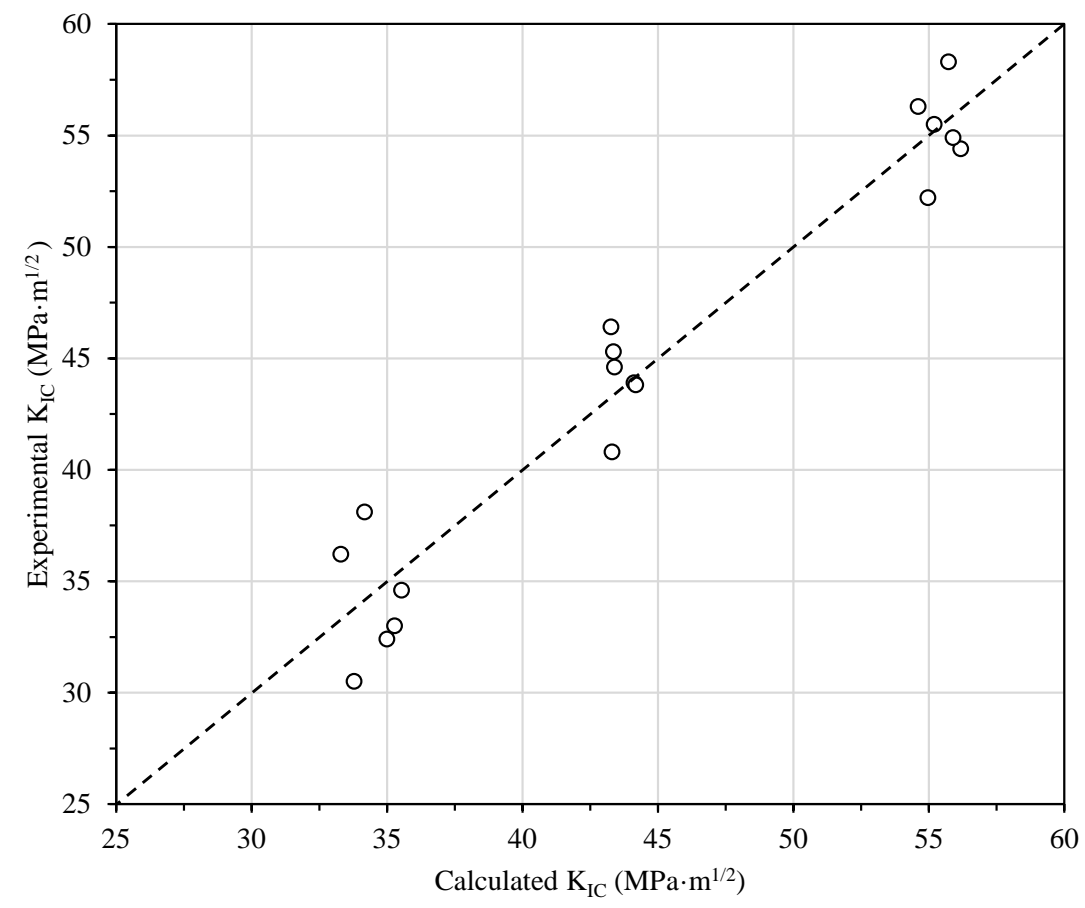

Figure 16. Comparison of calculated and measured values of $\mathrm{K}_{\mathrm{IC}}$. 


\section{CONCLUSIONS}

As stated in the results presented above, both thermal moduli and demolding times caused property variations between the Y2 wedges, the Y3 wedges and the bearing journals of the crankshafts from the same mold. These variations were reflected in microstructure (nodule count, pearlite interlamellar spacing and presence of residual ferrite) and in tensile properties. Nevertheless, the effect of temperature shows trends that are not geometry dependent for the tensile results, thus rendering valuable results on Y2 and Y3 wedges. For a given temperature, UTS, YS and hardness of the investigated pearlitic ductile iron appeared mainly affected by pearlite interlamellar spacing while nodule count shows a predominant effect on elongation at rupture.

The Y2 wedge results reported here can be used for performing comparisons with other past and future research works related or not to crankshafts, as Y2 wedge is a widespread cast iron sample manufacturing geometry. Nevertheless, the Y2 wedges could not be used for performing fracture toughness tests aimed at being representative of the bearing journal because the required plain strain condition would not be satisfied for a specimen machined out of them. This is especially critical in case of testing at high temperature.

This limitation has been overcome with Y3 wedges. The fracture toughness results obtained from these wedges represent better than yield strength or tensile strength the mechanical performance of the bearing journals because cleavage is reported as the failure mode for cast iron crankshafts. Furthermore, the use of yield strength and ultimate tensile strength for studying the mechanical response of the material underestimates the benefit of the heating up of lubricating oil to the working temperature on the performance of the material.

The interpretation of the toughness change with temperature that has been measured is valuable for the competition between casting and forging. As the toughness of the cast iron used to produce the crankshafts increases when the engine warms up and because the worst situation in terms of torque occurs when starting the vehicle, the fracture of a cast iron crankshaft should not happen once the vehicle is running if it did not happen right when the vehicle started. This leads to a relevant conclusion in terms of part safety in the competition between cast iron and forged steel crankshafts: although the pearlitic ductile cast iron of a crankshaft shows a brittle failure, this fact does not increase the risk of a failure once the vehicle started running.

Finally, an experimental fit has been proposed between the tensile test results from the Y2 wedges and the toughness measured on the Y3 wedges. This relation is expected to apply to any fully pearlitic ductile iron crankshafts whose manufacturing and microstructural conditions are similar to the ones employed in the study. This equation is intended to perform quick estimate of $\mathrm{K}_{\mathrm{IC}}$ for design purposes by using tensile test results on commonly used Y2 wedges.

\section{Acknowledgements}

The authors want to thank Draxton-Teruel Foundry for all the collaborating efforts made to produce the cast parts used in this study. This research did not receive any specific grant from funding agencies in the public, commercial or not-for-profit sectors.

\section{REFERENCES}

[1] I. V. Kudryavtsev, I. T. Goncharov, Comparison between the strength of steel and cast iron crankshafts in large-scale routine fatigue bending tests. Problemy Prochnosty, 1976, vol 9, pp. 99105. 
[2] J. Sertucha, R. Suárez, J. Izaga, L. A. Hurtado, J. Legazpi, Prediction of solid state structure based on eutectic and eutectoid transformation parameters in spheroidal graphite irons. Int. J. Cast Met. Res., 2006, vol 19, pp. 315-322. doi: 10.1179/136404606X167114

[3] M. Fonte, V. Infante, M. Freita, L. Reis, Failure mode analysis of two diesel engine crankshafts, Procedia Struct. Integr., 2016, vol 1, pp. 313-318. doi: 10.1016/j.prostr.2016.02.042

[4] D. Moore, K. Packer, A. Jones, D. Carlson, Crankshaft failure and why it may happen again, Prac. Fail. Anal., 2001, vol 1, pp. 63-72. doi: https://doi.org/10.1007/BF02715199

[5] O. Asi, Failure analysis of a crankshaft from ductile cast iron, Eng. Fail. Anal., 2006, vol 13, pp. 1260-1267. doi: https://doi.org/10.1016/j.engfailanal.2005.11.005

[6] X. Hou, Y. Li, T. Jiang, Fracture failure analysis of a ductile cast iron crankshaft in a vehicle engine, J. Fail. Anal. Prev., 2011, vol 11, pp. 10-16. doi: https://doi.org/10.1007/s11668-010-9406$\mathrm{Z}$

[7] N. V. Nallicheri, J. P. Clark, F. R. Field, Material alternatives for the automotive crankshaft; a competitive assessment based on manufacturing economics, SAE Technical Paper $\mathrm{N}^{\mathbf{0}}$. 910139, 1991. doi: https://doi.org/10.4271/910139

[8] F. Faura, Technical-economic models for materials systems analysis and their application to automotive parts fabrication, Rev. Met., 1996, vol 32, pp. 381-390.

[9] M. Zoroufi, A. Fatemi, A literature review on durability evaluation of crankshafts including comparisons of competing manufacturing processes and costa analysis, 26th Forging Industry Technical Conference, Chicago, IL, 2005.

[10] P. Citti, A. Giorgetti, U. Millefanti, Current challenges in material choice for high-performance engine crankshaft, Procedia Struct. Integr., 2018, vol 8, pp. 486-500. doi: https://doi.org/10.1016/j.prostr.2017.12.048

[11] M. Khameneh, M. Azadi, Evaluation of high-cycle bending fatigue testing and fracture behaviors in EN-GJS-2 ductile cast iron of crankshafts, Eng. Fail. Anal., 2018, vol 85, pp. 189-200. doi: https://doi.org/10.1016/j.engfailanal.2017.12.017

[12] J. Lacaze, J. Sertucha, Effect of $\mathrm{Cu}, \mathrm{Mn}$ and $\mathrm{Sn}$ on pearlite growth kinetics in as-cast ductile irons, Int. J. Cast Met. Res., 2016, vol 29, pp. 73-77. doi: 10.1179/1743133615Y.0000000031

[13] J. Serrallach, J. Lacaze, J. Sertucha, R. Suárez, A. Monzón, Effect of selected alloying elements on mechanical properties of pearlitic nodular cast irons, Key Eng. Mat., 2011, vol 457, pp. 361-366. doi: 10.4028/www.scientific.net/KEM.457.361

[14] ASTM, ASTM E399-17 Standard method for linear-elastic plane-strain fracture toughness $\mathrm{K}_{\mathrm{I}} \mathrm{c}$ of metallic materials, West Conshohocken: ASTM International, 2017.

[15] K. R. W. Wallin, Equivalent Charpy-V impact criteria for nodular cast iron, Int. J. Met., 2014, vol 8, pp. 81-86. doi: https://doi.org/10.1007/BF03355584

[16] G. Artola, I. Gallastegi, J. Izaga, M. Barreña, A. Rimmer, Austempered ductile iron (ADI) alternative material for high-performance applications, Int. J. Met., 2017, vol 11, pp. 131-135. doi: https://doi.org/10.1007/s40962-016-0085-8

[17] R. M. Metkar, V. K. Sunnapwar, S. D. Hiwase, V. S. Anki, M. Dumpa, Evaluation of FEM based fracture mechanics technique to estimate life of an automotive forged steel crankshaft of a single cylinder diesel engine, Proc. Eng., 2013, vol 51, pp. 567-572. Doi: https://10.1016/j.proeng.2013.01.080.

[18] R. K. Maurya, Reciprocating Engine Combustion Diagnostics, Springer Nature Switzerland AG., 2019, 223-280. Doi: https///doi.org/10.1007/978-3-030-11954-6_6

[19] S. Lee, Y. Chang, Fracture toughness and crack growth rate of ferritic and pearlitic compacted graphite cast irons at $25^{\circ} \mathrm{C}$ and $150^{\circ} \mathrm{C}$, Met. Trans. A, 1991, vol 22A, pp. 2645-2653.

[20] L. D’Agostino, A. De Santis, V. Di Cocco, D. Iacoviello, F. Iacoviello, Fatigue crack propagation in ductile cast irons: an artificial neural networks-based model, Proc. Struct. Int., 2017, vol 3, pp. 291-298. Doi: https://101016/j.str.2017.04.048 